\title{
1 Selenium isotope ratios, redox changes and biological productivity across the end-Permian mass extinction
}

3

1

3

1. Department of Earth \& Space Sciences and Astrobiology Program, University of Washington,

\author{
Eva E. Stüeken ${ }^{1 *}$, Julien Foriel $^{1, \star}$, Roger Buick $^{1}$, Shane D. Schoepfer ${ }^{1}$
}

\section{Seattle, WA 98195-1310, USA}

† present address: Tokyo Institute of Technology, Earth-Life Science Institute (ELSI), 2-12-1 IE-

13 Ookayama, Meguro-ku, Tokyo, 152-8550, Japan

* corresponding author. evast@uw.edu

\section{Abstract}

The causes of the greatest known mass extinction in Earth's history, in the latest Permian, remain actively debated. Here we use Se isotopes and abundances in marine sediments from an outer-shelf environment to test one of the most commonly cited hypotheses about the collapse of the biosphere, i.e. widespread euxinia in the open ocean. Our data show a small positive excursion in $\delta^{82 / 78}$ Se prior to the extinction, consistent with local euxinia. However, this was followed by a significant negative excursion with a minimum of $-1.8 \%$ (relative to NIST SRM 3149), immediately preceding the principal extinction horizon. A net fractionation of this magnitude likely resulted from partial reduction of Se oxyanions dissolved in the water column.

2 Due to their low abundance, Se oxyanions are rapidly scavenged in anoxic basins or regions of high biological productivity with little net isotopic fractionation. We therefore interpret the 
24 uniquely negative fractionations in this section as an indicator for relatively oxygenated

25 conditions in this marine basin at the time when biological productivity declined. The offset

26 between the peak excursion and the major extinction horizon possibly reflects a slow-down in

27 ocean circulation leading to nutrient limitation, which may thus have prohibited a rapid recovery

28 of the local biosphere in the early Triassic. Although we are unable to extrapolate to the global

29 ocean due to the short residence time of Se in seawater, our data are thus consistent with the

30 newly emerging view that euxinia developed along ocean margins and in oxygen minimum

31 zones before the extinction, but was probably replaced by (sub-)oxic conditions during the $\sim 1$

32 kyr peak productivity decline and was thus not solely responsible for the extinction event.

\section{1. Introduction}

The latest Permian featured the largest known mass extinction in Earth's history (251.0

36 Myr, Burgess et al., 2014), yet the causes and consequences are still not well understood (e.g.

37 Erwin et al., 2002; White, 2002). While ocean euxinia (a state of anoxia with abundant dissolved

$38 \mathrm{~S}^{-\mathrm{II}}$ in the water column) is widely considered to be a factor contributing to the extinction (e.g.

39 Grice et al., 2005; Kump et al., 2005; Wignall and Twitchett, 1996), the geographic extent and

40 duration of euxinic conditions in different ocean environments remain uncertain. Perturbations in

41 sulfur isotopes (e.g. Kajiwara et al., 1994; Luo et al., 2010) and widespread occurrences of

42 pyritic black shale (e.g. Wignall and Twitchett, 2002) have been interpreted as evidence for

43 euxinia, but new data from transition element abundances and isotopes suggest that euxinia was

44 localized along continental margins and in mid-water oxygen minimum zones, while large parts

45 of the continental shelves remained oxic during the extinction event (Algeo et al., 2010; Algeo et

46 al., 2011; Brennecka et al., 2011; Proemse et al., 2013). It is therefore uncertain if euxinia was 
47 indeed the primary kill mechanism resulting in a catastrophic loss of marine diversity (cf. Grice

48 et al., 2005; Kump et al., 2005; Wignall and Twitchett, 1996). Furthermore, it is also not well

49 known if biological productivity actually declined during the extinction event. There is no

50 independent evidence for a decline in net biological productivity and organic-matter export at

51 this time, other than theoretical models of total carbon fluxes (Algeo et al., 2013; Shen et al.,

52 2014). So, despite paleontological evidence of a $>90 \%$ mass extinction among macro-

53 organisms, it is conceivable that algal and microbial organisms maintained a high flux of organic

54 matter to the sediments even though bulk productivity shifted from eukaryotic to prokaryotic

55 plankton during the extinction event (Cao et al., 2009; Luo et al., 2013; Xie et al., 2005).

56 Selenium isotopic ratios represent a newly emerging biogeochemical proxy (e.g. Mitchell et al.,

57 2012; Wen et al., 2014) that may help constrain our understanding of changes in ocean redox

58 state and productivity associated with the latest-Permian mass extinction. The processes that

59 control the partitioning of Se isotopes in marine environments are not yet fully understood, but

60 existing information reviewed below and elsewhere (Stüeken et al., 2015b)allows us to construct

61 hypotheses that we seek to test in this study.

62 In the modern oxic ocean, Se is mainly present as oxyanions (both $\mathrm{Se}^{\mathrm{IV}}$ and $\mathrm{Se}^{\mathrm{VI}}$ ), and it

63 shows a nutrient-type profile in the water column, with lowest concentrations in the surface layer

64 and nearly constant levels below (Cutter and Cutter, 2001). This behavior reflects Se uptake into

65 biomass in the photic zone, forming organic $\mathrm{Se}^{-\mathrm{II}}$, and subsequent re-oxidation of organic $\mathrm{Se}^{-\mathrm{II}}$ at

66 depth (Cutter and Bruland, 1984). In sediments, especially under anoxic conditions, organic Se ${ }^{-\mathrm{II}}$

67 is usually a major component of the total $\mathrm{Se}$ content, in addition to $\mathrm{Se}^{0}$, inorganic $\mathrm{Se}^{-\mathrm{II}}$ and

68 adsorbed Se $\mathrm{IV}^{\mathrm{IV}}$ (Fan et al., 2011; Kulp and Pratt, 2004). In anoxic basins, the organic Se $\mathrm{e}^{-\mathrm{II}}$ 
component is likely enhanced because remineralization of organic matter is suppressed (Cutter,

70 1982; Cutter, 1992).

71 Se isotopes (here reported as $\delta^{82 / 78}$ Se relative to NIST SRM 3149) are fractionated by up

72 to $25 \%$ during $\mathrm{Se}^{\mathrm{VI}}$ and $\mathrm{Se}^{\mathrm{IV}}$ reduction to $\mathrm{Se}^{0}$ or inorganic $\mathrm{Se}^{-\mathrm{II}}$ where the residual oxyanions

73 become isotopically enriched (Ellis et al., 2003; Herbel et al., 2000; Johnson and Bullen, 2003;

74 Johnson et al., 1999). Fractionations are generally smaller when these reduction reactions are

75 biologically catalyzed (max. 14\%o in microbial cultures) and perhaps significantly smaller in

76 natural environments where the supply of Se oxyanions and reductants (organic or inorganic)

77 may be lower (Johnson and Bullen, 2004). However, individual reports of fractionations over a

78 range of several permil in marine sediments (e.g. Stüeken et al., 2015b; Wen et al., 2014, this

79 study) suggest that Se oxyanion reduction can leave a detectable signature in the rock record.

80 Fractionations associated with assimilation into biomass and $\mathrm{Se}^{\mathrm{IV}}$ adsorption are minor, up to

$810.6 \%$ in favor of the lighter isotopes (Clark and Johnson, 2010; Johnson et al., 1999; Mitchell et

82 al., 2013). Biomass forming in the photic zone (+0.3\%o, Mitchell et al., 2012), where Se is

83 quantitatively consumed, may thus record the composition of $\mathrm{Se}^{\mathrm{IV}}$ and $\mathrm{Se}^{\mathrm{VI}}$ in seawater, or at

84 least provide a minimum constraint; assuming fractionation of $0.6 \%$ during assimilation into

85 biomass (Clark and Johnson, 2010), seawater Se oxyanions may be as heavy as $+0.9 \%$. It is

86 plausible that this small isotopic enrichment of dissolved Se oxyanions relative to the Earth's

87 crust $(0.0 \pm 0.5 \%$, Rouxel et al., 2002) results from non-quantitative Se oxyanion reduction in

88 suboxic environments, such as in local oxygen minimum zones or in sedimentary pore waters,

89 i.e. in environments that are directly connected to the relatively large Se oxyanion supply from

90 the open ocean . Reduction likely occurs concurrently with denitrification, i.e. at higher Eh than

91 sulfate reduction (e.g. Oremland, 1990). We would therefore predict that sediments from suboxic 
92 settings contain some proportion of isotopically light reduced Se phases, including $\mathrm{Se}^{0}$ and/or $\mathrm{Se}^{-}$

93 II. Data from bulk sediments of the oxygen minimum zone in the Arabian Sea $(-0.07 \pm 0.08 \%$,

94 Mitchell et al., 2012) and from the Bermuda rise in the open Atlantic ocean $(-0.10 \pm 0.16$,

95 Mitchell et al., 2012) may indeed reflect the presence of an isotopically negative reduced Se

96 phase that may have formed during Se oxyanion reduction in the water column or during

97 diagenesis. Sequential extraction would be necessary to test this conclusion. In contrast,

98 sediments that are dominated by organic Se $(+0.3 \%$, Mitchell et al., 2012) due to high biological

99 productivity or where Se oxyanion reduction is relatively more quantitative than in the open

100 ocean, should on average be isotopically heavy. Values from the oceanographically restricted

101 Black Sea, which is largely anoxic and dominated by $\mathrm{S}^{-\mathrm{II}}$ at depth (i.e. euxinic), are indeed

102 isotopically heavy $(+0.22 \pm 0.14 \%$, Mitchell et al., 2012) compared to the sediments from the

103 open ocean quoted above. We note that this includes data from oxic parts of the Black Sea

$104(+0.29 \pm 0.07 \%$, Mitchell et al., 2012), but the overall scarcity of Se oxyanions in this restricted

105 basin (Cutter, 1982; Cutter, 1992) makes it unlikely that those sediments contain a significant

106 proportion of reduced Se phases that were formed by non-quantitative Se oxyanion reduction.

107 These observations suggest that Se isotopes in ancient marine sediments can be used to

108 draw inferences about productivity and redox state of the overlying water column. Positive

109 values in bulk sediments should be indicative of high biological productivity and/or anoxic

110 conditions. The former would result in an overabundance of isotopically heavy biomass $(+0.3 \%$

111 in today's open ocean, Mitchell et al., 2012) over other Se phases, whereas the latter results in

112 nearly quantitative Se oxyanion reduction and further enhances organic matter preservation. For

113 example, Mitchell et al. (2012) found predominantly positive values $(+0.3 \pm 0.3 \%)$ in variety of

114 Phanerozoic rocks with high total organic carbon contents (TOC $10.6 \pm 6.9 \%$ ), irrespective of 
115 redox state. High biological productivity and hence organic Se may have dominated in those

116 sediments. Negative isotopic composition of less than $-1 \%$, i.e. lighter than the crust $(0.0 \pm$

$1170.5 \%$, Rouxel et al., 2002) and potential fractionations by adsorption or assimilation $(\leq 0.6 \%$,

118 Clark and Johnson, 2010; Johnson et al., 1999; Mitchell et al., 2013), should in turn be indicative

119 of oxic to suboxic conditions and low biological productivity, because then organic Se is less

120 abundant and Se oxyanions can be reduced non-quantitatively in pore waters or in oxygen

121 minima in the water column. In other words, negative values should reflect a high Se oxyanion

122 supply relative to the demand. Wen et al. (2014) recently observed negative $\delta^{82 / 78}$ Se values down

123 to $-3.3 \%$ in very Se-rich Cambrian sediments (up to $121 \mathrm{ppm} \mathrm{Se}$ ) that were deposited under an

$124 \mathrm{Fe}^{2+}$-dominated water column. Such ferruginous conditions can be classified as suboxic if sulfate

125 was stable in the water column (which is unknown) and may thus not have been conducive for

126 rapid quantitative Se reduction, especially if Se input was high. Importantly, both Wen et al.

127 (2014) and Mitchell et al. (2012) found relatively more negative $\delta^{82 / 7}$ Se values in sediments

128 with molar $\mathrm{Se} / \mathrm{TOC}$ ratios greater than $\sim 10^{-5}$, i.e. when the $\mathrm{Se} / \mathrm{TOC}$ ratio exceeded that of marine

129 biomass $\left(2 \cdot 10^{-6}\right.$ to $6 \cdot 10^{-6}$, Mitchell et al., 2012). Hence light sedimentary $\delta^{82 / 78}$ Se values (-1\%o or

130 less) likely reflect the presence of a significant Se oxyanion reservoir in seawater and by

131 extension, absence of euxinia and relatively low productivity. Se isotopes therefore have the

132 potential to test the validity of the newly emerging picture of the latest Permian mass extinction,

133 i.e. the collapse of biological productivity under non-euxinic conditions in the open ocean.

134 In this study, we present whole-rock Se isotope and abundance data from a marine

135 stratigraphic section across the latest Permian extinction horizon. In addition, as a proof of

136 concept, we sequentially extracted different Se phases from one sample and show that they are

137 isotopically distinct, consistent with our interpretation of the bulk data. Sequential extraction 
138 analyses thus have the potential to provide additional information (see also Fan et al., 2011;

139 Schilling et al., 2014) and should be revisited in future studies, but we emphasize that the focus

140 of this study is on bulk rocks. We conclude that bulk Se isotopes can be a valuable new

141 biogeochemical proxy in deep time, where in our case a large negative excursion reveals a

142 decline of macro-biological productivity in oxic to suboxic ocean waters in the late Permian. The

143 short residence time of Se in seawater ( 26 kyr today, Henderson and Henderson, 2009) may

144 imply that our results are only representative of this local basin and cannot be extrapolated to the 145 global ocean, but we hope that this will be tested in future studies.

\section{Geologic Setting}

148 Our samples are from outcrops of the Ranger Canyon and the unconformably overlying

149 Sulphur Mountain Formations in the Western Canada Sedimentary Basin at Opal Creek,

150 Kananaskis Valley, southwest Alberta (Farley et al., 2005; Henderson, 1997; Schoepfer et al.,

151 2012). As evidenced by the abundance of cold-water sponge spicules and phosphatic material

152 and the absence of shallow-water sedimentary features (Henderson, 1997), these marine

153 sediments were probably deposited in an outer shelf setting, named the Ishbel Trough

154 (Henderson et al., 1994), along the eastern margin of the Panthalassic Ocean (Henderson, 1997;

155 Henderson et al., 1994). Although it is possible that the Ishbel Trough was located inboard of a

156 volcanic arc, molar Mo/U ratios of $0.3 \pm 0.2$ times that of seawater (Schoepfer et al., 2013)

157 indicate open exchange with the global ocean (Algeo and Tribovillard, 2009). Furthermore, high

158 nitrogen isotope ratios of up to $+10 \%$ and trace metal concentrations significantly above detrital

159 background suggest that during the mid-Permian this site was located in an area with a

160 significant influx of nutrients from the sea, possibly due to upwelling of deep water along the 
161 continental margin (Schoepfer et al., 2013; Schoepfer et al., 2012). This nutrient influx probably

162 led to moderately high primary productivity and a water column oxygen-minimum zone

163 (Georgiev et al., 2015; Schoepfer et al., 2013; Schoepfer et al., 2012). Productivity likely peaked

164 in the late Permian, resulting in a brief episode of euxinia. Productivity is then thought to have

165 declined as the ocean warmed under a $\mathrm{CO}_{2}$-enriched atmosphere and circulation slowed down

166 (Schoepfer et al., 2013; Schoepfer et al., 2012).

The samples we analyzed span the time interval from when productivity was highly

168 active in the Middle and Late Permian, until well after the principal extinction horizon but before

169 the paleontologically defined recovery period. The extinction event itself is marked by the abrupt

170 disappearance of sponge spicules and bioturbation $\sim 40 \mathrm{~cm}$ above the Ranger Canyon-Sulphur

171 Mountain unconformity (Schoepfer et al., 2012) (labeled 'EXT' in Fig. 1) whereas the

172 biostratigraphic Permian-Triassic boundary occurs $\sim 1.1 \mathrm{~m}$ above the extinction horizon.

173 Assuming an average sedimentation rate of $2 \mathrm{~cm} \mathrm{kyr}^{-1}$ for this section (Farley et al., 2005), the

174 time span between the unconformity and the extinction horizon is approximately $20 \mathrm{kyr}$, which is

175 the close to the residence time of selenium in the modern ocean (26 kyr, Henderson and

176 Henderson, 2009). The unconformity between the Ranger Canyon and Sulphur Mountain

177 Formations represents a time gap of 5-7 Myr, representing the entire Wuchiapingian stage and

178 part of the Changhsingian stage.

179 Though bedding is tilted to near vertical, the rocks have experienced only moderate burial

180 temperatures $\left(<150^{\circ} \mathrm{C}\right)$ as constrained by the Conodont Alteration Index (Schoepfer et al.,

181 2012). Chemical weathering is limited to a thin surface layer (see also Georgiev et al., 2015),

182 which can be removed with a rock saw. We are therefore confident that our measured isotope

183 ratios are not affected by alteration (cf. Zhu et al., 2014). Lithologies are predominantly 
184 spiculitic chert and silicified siltstones in the Ranger Canyon Fm., and organic-rich and variably

185 sulfidic shales to siltstones in the overlying Sulphur Mountain Fm. (Fig. 1).

187 3. Methods

188 3.1. Bulk sample preparation

189 A detailed description of our sample preparation and analytical protocol is given in

190 Stüeken et al. (2013). We used two slightly different preparation procedures (methods D and E

191 in Stüeken et al., 2013, and in Table 1) for this sample set, because method development was

192 still in progress during the initial stages of this study. All samples were digested with HF,

$193 \mathrm{HClO}_{4}$, and $\mathrm{HNO}_{3}$ and $\mathrm{Se}$ was separated from the matrix by filtration through a column of thiol

194 cotton fibers (TCF). The Se was then desorbed with $\mathrm{HNO}_{3}$, partially evaporated and redissolved 195 in $\mathrm{HCl}$ for analysis. The two preparation procedures differ in that some samples were treated 196 with aqua regia after column filtration to further minimize Ge concentrations (method E), 197 whereas most samples were not (method D). But as shown in Table 1, we do not observe any 198 systematic differences between the two methods.

\subsection{Sequential extraction of selenium phases}

201 One sample (position $-40 \mathrm{~cm}$ ) was subjected to a sequential extraction procedure to 202 separate three different selenium phases (Fig. 2) (e.g. Schilling et al., 2014): first adsorbed $\mathrm{Se}^{\mathrm{IV}}$, 203 second inorganic $\mathrm{Se}^{-\mathrm{II}}$ bound to pyrite and possibly $\mathrm{Se}^{0}$, and third refractory organic $\mathrm{Se}^{-\mathrm{II}}$ and 204 residual $\mathrm{Se}^{0}$. Traces of $\mathrm{Se}^{0}$ may be contained in both fractions two and three because we could 205 not extract it separately. The stratigraphic level of $-40 \mathrm{~cm}$ was chosen because that part of the 206 section is below any isotopic excursions and so represents background conditions. The protocol 
207 was adapted from Kulp \& Pratt (2004) and carried out on four sample aliquots. Errors reported in

208 the results are equal to the standard deviation between those four separate aliquots. Initial tests

209 showed that acetic-acid-soluble, phosphate-exchangeable and water-soluble Se (e.g. Kulp and

210 Pratt, 2004; Martens and Suarez, 1997; Wright et al., 2003) were below detection limit $(<0.1 \mathrm{ppb})$

211 and thus were ignored in the final protocol.

212 * NaOH-soluble selenium: $\mathrm{Se}^{\mathrm{IV}}$ strongly adsorbed to oxides and clay minerals as well as labile

213 organic $\mathrm{Se}^{-\mathrm{II}}$ compounds are soluble in $\mathrm{NaOH}$ (Kulp and Pratt, 2004; Martens and Suarez, 1997).

214 For extraction of this phase, $5 \mathrm{~g}$ of rock powder were weighed into $50 \mathrm{ml}$ polypropylene

215 centrifuge tubes and mixed with $50 \mathrm{ml}$ of $0.1 \mathrm{M} \mathrm{NaOH}$ for $2 \mathrm{~h}$ in a $90^{\circ} \mathrm{C}$ water bath. The powder

216 was kept in suspension with a magnetic stir bar. After cooling to room temperature, the solution

217 containing the desorbed Se was separated by centrifugation for 20 minutes. The residual powder

218 was washed with $20 \mathrm{ml} \mathrm{DI}-\mathrm{H}_{2} \mathrm{O}$, which was added to the $\mathrm{NaOH}$ solution. This solution was then

219 filtered twice through a $0.2 \mu \mathrm{m}$ pore-size filter to remove colloidal particles, acidified with 8.86

$220 \mathrm{ml}$ of $6 \mathrm{~N} \mathrm{HCl}$, and then passed through a TCF column. All subsequent steps followed the bulk

221 sample protocol (using the method without aqua regia). Because the sample was not subject to

222 oxidation during or after $\mathrm{NaOH}$ leaching, any labile organic $\mathrm{Se}^{-\mathrm{II}}$ extracted by $\mathrm{NaOH}$ should not

223 have been captured by the TCF, which is optimized for $\mathrm{Se}^{\mathrm{IV}}$ (Yu et al., 2002). However, we

224 cannot exclude the possibility that $\mathrm{O}_{2}$ dissolved in the $\mathrm{NaOH}$ or $\mathrm{HCl}$ oxidized some of the labile

225 organic $\mathrm{Se}^{-\mathrm{II}}$ or inorganic reduced Se phases. This fraction will therefore be referred to simply as

226 the $\mathrm{NaOH}$ extract. The residual sample powder was dried in a $60^{\circ} \mathrm{C}$ oven over night.

227 * Cr-reducible selenium: Chromium reduction is commonly used to extract inorganic sulfides

228 from bulk rocks (Canfield et al., 1986) and thus would extract inorganic $\mathrm{Se}^{-\mathrm{II}}$ contained in sulfide

229 minerals. This step may also mobilize $\mathrm{Se}^{0}$ as it does $\mathrm{S}^{0}$ (e.g. Gröger et al., 2009). We used a 
230 diffusion process adapted from Burton et al. (2008), Ulrich et al (1997) and Hsieh \& Shieh

231 (1997). Two grams of rock powder were weighed into a 200ml serum bottle and wetted with a

232 few drops of DI- $\mathrm{H}_{2} \mathrm{O}$. Three $5 \mathrm{ml}$ pyrex test tubes were added to the bottle and filled by a syringe

233 with $4 \mathrm{ml}$ of $\mathrm{N}_{2}$-purged $\mathrm{Zn}$-acetate solution ( $10 \%$ by weight) under a constant stream of $\mathrm{N}_{2}$ gas.

234 The bottle was then capped with a vacuum-tight rubber septum and evacuated and purged with

$235 \mathrm{~N}_{2}$ three times through a needle. Then $15 \mathrm{ml}$ of $12 \mathrm{~N} \mathrm{HCl}$ and $15 \mathrm{ml}$ of $2 \mathrm{M} \mathrm{CrCl}_{2}$ were added

236 sequentially through the needle with a syringe. Both solutions were previously purged with $\mathrm{N}_{2}$

237 gas for two hours. The $\mathrm{CrCl}_{2}$-solution was prepared from $\mathrm{CrCl}_{3}$ by reduction with mossy zinc in

$2380.5 \mathrm{M} \mathrm{HCl}$ (Hsieh and Shieh, 1997; Hsieh and Yang, 1989). After addition of all reagents, the

239 serum bottles were sonicated for 20 minutes and placed on an orbital shaker for two days.

240 Sonication was repeated on the second day. Zinc sulfide and ZnSe that precipitated in the Zn

241 acetate traps were transferred together with residual $\mathrm{Zn}$ acetate into a $90 \mathrm{ml}$ Teflon beaker and

242 mixed with $10 \mathrm{ml} \mathrm{HClO}_{4}$ and $10 \mathrm{ml}$ concentrated $\mathrm{HNO}_{3}$. The beaker was capped tightly and left at

$243130^{\circ} \mathrm{C}$ overnight. Subsequent extraction of selenium with TCF followed the bulk sample

244 protocol. Residual rock powder was transferred from the serum bottle into a centrifuge tube,

245 washed three times with DI- $\mathrm{H}_{2} \mathrm{O}$, and dried at $60^{\circ} \mathrm{C}$ overnight.

$246 *$ Total residual selenium: The residual powder contained refractory organic $\mathrm{Se}^{-\mathrm{II}}$ and residual

$247 \mathrm{Se}^{0}$. All rock powder remaining from the Cr-reduction was transferred into a 90ml Teflon beaker

248 and digested following the same protocol as for bulk samples.

249 Selenium abundances in each phase were calculated relative to the initial bulk sample,

250 assuming that the total mass loss associated with $\mathrm{NaOH}$ desorption was negligible. This

251 assumption is not required for Cr-reduction, because here the remaining rock powder is

252 transferred quantitatively to the subsequent step. 


\section{$254 \quad 3.3$. Isotopic analyses}

Analyses were carried out by multi-collector inductively-coupled plasma mass-

256 spectrometry ( $\mathrm{Nu}$ Instruments), where $\mathrm{Se}$ was introduced as $\mathrm{H}_{2} \mathrm{Se}$ through a cold-vapor hydride

257 generator (Cetac HGX-200). Analytical parameters are described in more detail in Stüeken et al.

258 (2013). Instrumental mass bias was corrected by standard-sample bracketing. Interferences with

$259{ }^{74,76,78}(\mathrm{ArAr}),{ }^{76}(\mathrm{AsH})$ and ${ }^{74,76} \mathrm{Ge}$ were corrected post-analytically (Stüeken et al., 2013). Unless

260 otherwise noted, all results are reported in terms of ${ }^{82} \mathrm{Se} /{ }^{78}$ Se relative to NIST SRM 3149:

$$
\left.\delta^{82 / 78} \mathrm{Se}[\% \mathrm{o}]=\left(\left({ }^{82} \mathrm{Se} /{ }^{78} \mathrm{Se}\right)_{\text {sample }} /\left({ }^{82} \mathrm{Se} /{ }^{78} \mathrm{Se}\right)_{\mathrm{SRM} 3149}\right)-1\right) \cdot 1000
$$

262 because this is the most precise ratio using our protocol. It avoids isobaric interferences with

$263{ }^{76} \mathrm{Ge}$ and ${ }^{76}(\mathrm{AsH})$ and only suffers from comparatively minor interferences with ${ }^{78}(\mathrm{ArAr})$ and

$264{ }^{82} \mathrm{Kr}$, which makes it more reliable than $\delta^{82 / 76} \mathrm{Se}$ for complex geochemical matrices. Three-

265 isotope diagrams (Fig. 3) show that within error our data plot along the predicted mass-

266 dependent fractionation line, indicating that all major interferences have been corrected and that

267 mass-independent fractionation is absent. Thus $\delta^{82 / 78}$ Se values can be multiplied by 1.54 to

268 convert them to the more commonly used $\delta^{82 / 76}$ Se ratio. Our average precision for $\delta^{82 / 78}$ Se, here

269 defined as the average standard deviation of replicate analyses, was $0.16 \%$, and the average

270 relative error for total Se concentrations was 7\%. Analyses of the USGS rock standard SGR-1

271 gave a value of $-0.38 \pm 0.44 \%$ o $(2 \sigma, \mathrm{n}=9)$ when treated with method $\mathrm{D}$ and a value of $+0.05 \pm$

$2720.38 \%(2 \sigma, \mathrm{n}=9)$ when treated with method E (Stüeken et al., 2013). The difference between

273 the two methods is consistently smaller in other types of samples, which, as discussed by

274 Stüeken et al. (2013), may be due to the relatively low thermally maturity of the SGR-1 oil shale.

275 Published values for SGR-1 range from $-0.13 \pm 0.06 \%$ ( $2 \sigma, \mathrm{n}=11$, Mitchell et al., 2012) to 
$276+0.40 \pm 0.42 \%$ o $\left(2 \sigma, \mathrm{n}=3\right.$, Layton-Matthews et al., 2006), converted to $\delta^{82 / 78}$ Se and the NIST

277 SRM 3149 scale after Carignan \& Wen (2007). Part of this spread may also reflect sample

278 heterogeneity. In the following discussion all literature values were converted to $\delta^{82 / 78}$ Se for

279 better comparison, assuming strictly mass-dependent behavior. Literature values reported as

$280 \delta^{80 / 76}$ Se were not converted, because they only differ from $\delta^{82 / 78}$ Se by a factor of 1.05 , which is

281 negligible within error.

282

283 3.4. Carbon and sulfur isotope analyses

284 Data of organic C and total S abundances and isotopes are mostly taken from Schoepfer

285 et al. (2013). We added a few additional analyses (at $-40,-21,+3,+4,+5,+6$ and $+8 \mathrm{~cm}$ ) to

286 increase stratigraphic resolution. Sample preparation and analyses were carried out with the same

287 protocol and facilities as described by Stüeken (2013) and Schoepfer et al. (2013). For TOC, the

288 average relative error (RE) was $15 \%$, and the average standard deviation for $\delta^{13} \mathrm{C}_{\mathrm{org}}$ (values

289 relative to VPDB) was $0.3 \%$. For total sulfur, the average RE was $7 \%$, and the average standard

290 deviation for $\delta^{34} \mathrm{~S}$ (values relative to VCDT) was $0.5 \%$.

291

\section{3.5. Fractionation model description}

293 We used a standard mass balance model of isotope fractionation to provide a framework

294 for a quantitative evaluation of the isotope data. The isotopic composition of complementary

295 oxidized $\left(\delta^{82 / 78} \mathrm{Se}^{\mathrm{VI} / \mathrm{IV}}\right)$ and reduced $\left(\delta^{82 / 78} \mathrm{Se}^{\text {red }}\right)$ selenium phases is a function of the fraction $(f)$ of

296 oxidized Se remaining in the system and the fractionation factor $(\alpha)$ of the reduction reaction (cf.

297 Canfield, 2001). The fractionation factor is related to the maximum fractionation $\left(\varepsilon \approx \delta^{82 / 78} \mathrm{Se}^{\mathrm{VI} / \mathrm{IV}}\right.$

$\left.298-\delta^{82 / 78} \mathrm{Se}^{\text {red }}\right)$ via the following approximation which is accurate for delta values of a few permil: 


$$
\varepsilon \approx 1000 \cdot(\alpha-1)
$$

300 In an open, steady-state system with progressive reduction, the composition of residual $\mathrm{Se}^{\mathrm{VI}}$

$301\left(\delta^{82 / 78} \mathrm{Se}^{\mathrm{VI}}{ }_{\text {res }}\right)$ evolves from its initial value $\left(\delta^{82 / 78} \mathrm{Se}^{\mathrm{VI}}\right.$ in $)$ as follows:

$$
\delta^{82 / 78} \mathrm{Se}^{\mathrm{VI} / \mathrm{IV}}{ }_{\text {res }}=\left(\left(\delta^{82 / 78} \mathrm{Se}_{\text {in }}^{\mathrm{VI}} /(1-\mathrm{f})\right)+((\alpha-1) / \alpha) \cdot 10^{3}\right) /((1 / \alpha)+\mathrm{f} /(1-\mathrm{f}))
$$

303 In a closed system, where the Se demand exceeds the supply, isotopic fractionation is described

304 by Rayleigh fractionation:

$$
\delta^{82 / 78} \mathrm{Se}_{\text {res }}^{\mathrm{VI} / \mathrm{IV}}=\left(\delta^{82 / 78} \mathrm{Se}_{\text {in }}^{\mathrm{VI}}+1000\right) \cdot \mathrm{f}^{(1-\alpha)}-1000
$$

306 In both systems, the composition of cumulative reduced $\mathrm{Se}\left(\delta^{82 / 78} \mathrm{Se}^{\mathrm{red}}\right)$ can be obtained by mass 307 balance:

$$
\delta^{82 / 78} \mathrm{Se}^{\mathrm{red}}=\left(\delta^{82 / 78} \mathrm{Se}^{\mathrm{VI}}{ }_{\text {in }}-\delta^{82 / 78} \mathrm{Se}^{\mathrm{VI} / \mathrm{IV}}{ }_{\text {res }} \cdot \mathrm{f}\right) /(1-\mathrm{f})
$$

309 The initial composition of $\mathrm{Se}^{\mathrm{VI} / \mathrm{IV}}$ entering the ocean $\left(\delta^{82 / 78} \mathrm{Se}^{\mathrm{VI} / \mathrm{IV}}\right.$ in $)$ is assumed to be $0 \%$, i.e.

310 equal to that of bulk Earth (Rouxel et al. 2002, converted to NIST scale after Carignan and Wen,

311 2007). The maximum observed fractionation associated with biotic reduction of Se oxyanions to

$312 \mathrm{Se}^{0}$ is $14 \%$ (Johnson and Bullen, 2004, excluding abiotic fractionation, which can be up to

$31325 \%$ ), but because most unaltered sediments display $\delta^{82 / 78}$ Se values within a small range of $-2 \%$

314 to +2\%o (Johnson and Bullen, 2004; Mitchell et al., 2012, this study; Shore, 2010; Stüeken et al.,

315 2015a; Stüeken et al., 2015b), it is unknown if fractionations of this magnitude occur under

316 natural marine conditions with low Se supply. We therefore use $2 \%$ and $14 \%$ as the two end-

317 members to calculate typical and extreme values for $f$ (Fig. 4). Because of this relatively small

318 range in $\delta^{82 / 78}$ Se values in natural samples compared to laboratory experiments, it is not possible

319 to distinguish between $\mathrm{Se}^{\mathrm{VI}}$ and $\mathrm{Se}^{\mathrm{IV}}$ reduction to $\mathrm{Se}^{0}$. However, it is likely that these two

320 oxidized species are isotopically similar in the modern ocean, because they are generated by 
321 oxidation of organic matter (Cutter and Bruland, 1984), a process which does not induce isotopic

322 fractionation (Johnson et al., 1999).

\section{4. Results}

\section{4.1. Bulk selenium isotope data}

Our results show a brief positive isotopic excursion in $\delta^{82 / 78} \mathrm{Se}$ followed by a large

327 negative excursion leading up to the main extinction horizon (Fig. 1, Table 2). We divided our

328 dataset into four stages, capturing the time before the positive excursion $(-40 \mathrm{~cm}$ to $+3.5 \mathrm{~cm}$,

329 stage I), the positive excursion itself $(+4 \mathrm{~cm}$ to $+9 \mathrm{~cm}$, stage II $)$, the negative excursion $(+10.5$

$330 \mathrm{~cm}$ to $+46 \mathrm{~cm}$, stage III) and the return to stability $(+49.9 \mathrm{~cm}$ to $1684 \mathrm{~cm}$, stage IV). In stage I,

$331 \delta^{82 / 78}$ Se averages $+0.05 \pm 0.62 \%$ o $(2 \sigma, \mathrm{n}=6)$. We note that after exclusion of the data point at

$332+1.5 \mathrm{~cm}$ (because it lies outside the $2 \sigma$ uncertainty range of the other five data points and may be

333 an outlier) stage I has a slightly negative average of $-0.07 \pm 0.12 \%$ o $(2 \sigma)$, in good agreement with

334 values from an upwelling zone in the modern Arabian Sea $(-0.07 \pm 0.16 \%$, $2 \sigma$, Mitchell et al.,

335 2012). Apart from this outlier, the $\delta^{82 / 78}$ Se record in stage I does not show a pronounced

336 discontinuity across the unconformity. In stage II, $\delta^{82 / 78}$ Se increases to $+0.55 \pm 0.42 \%$ o $(2 \sigma, \mathrm{n}=$

337 5). This small but statistically significant $\left(\mathrm{p}_{\text {one-tailed }}=0.01\right)$ positive excursion coincides with a

338 pyrite-rich bed and a positive excursion in organic carbon isotopes (Schoepfer et al., 2013).

339 Above the pyrite bed and extending up to the main extinction horizon (stage III), $\delta^{82 / 78}$ Se

340 decreases to a minimum of $-1.8 \pm 0.6 \%$ ( $2 \sigma)$ followed by a steady recovery back to $\sim-0.5 \%$ by

341 the time of peak metazoan extinction. This large negative excursion coincides with declines in

$342 \delta^{34} \mathrm{~S}, \delta^{13} \mathrm{C}_{\text {org }}$ and total organic carbon (TOC) during this stage (Schoepfer et al., 2013; Schoepfer

343 et al., 2012). In stage IV, $\delta^{82 / 78}$ Se gradually increases to around $+0.3 \%$ at the Permian-Triassic 
344 boundary $(100 \mathrm{~cm})$, which is similar to the proposed minimum composition of modern seawater

$345 \mathrm{Se}^{\mathrm{IV}}$ and $\mathrm{Se}^{\mathrm{VI}}$ (Mitchell et al., 2012; Rouxel et al., 2004). Both $\delta^{34} \mathrm{~S}$ and $\delta^{13} \mathrm{C}_{\text {org }}$ remain low, and

346 TOC reaches values of up to $2 \%$. The transition from stage III to stage IV is gradual and

347 apparently not controlled by facies changes.

\section{4.2. Sequential extraction experiment}

The three Se extracts from one sample $(-40 \mathrm{~cm}$; Table 3$)$ show distinct isotopic

351 compositions and abundances (Fig. 5). The residual fraction, i.e. refractory organic $\mathrm{Se}^{-\mathrm{II}}\left( \pm \mathrm{Se}^{0}\right)$

352 represents the major component, similar to samples analyzed in other studies (Fan et al., 2011;

353 Kulp and Pratt, 2004). Compared to the bulk sample, this fraction is isotopically slightly

354 enriched by $+0.20 \%$ in $\delta^{82 / 78}$ Se. The next most abundant species is the Cr-reducible Se, i.e.

355 inorganic $\mathrm{Se}^{-\mathrm{II}}\left( \pm \mathrm{Se}^{0}\right)$, followed by $\mathrm{NaOH}$-soluble $\mathrm{Se}$ (adsorbed $\mathrm{Se}^{\mathrm{IV}}$, possibly oxidized phases).

356 Their relative abundances are comparable to those reported from Cretaceous (Kulp and Pratt,

357 2004) and Cambrian samples (Fan et al., 2011). Both fractions are isotopically depleted relative

358 to the bulk sample $\left(\delta^{82 / 78} \mathrm{Se}=-0.17 \%\right.$ ) by $-0.74 \%$ and $-0.76 \%$, respectively.

359 Overall, nearly $92 \%$ of the total selenium was recovered by the sequential extraction

360 protocol. The weighted mean of the three fractions has an isotopic composition of $-0.16 \pm 0.24$

$361 \%(2 \sigma)$, i.e. only $0.01 \%$ heavier than the bulk sample. This very close agreement suggests that

362 the lost $8 \%$ belongs to the organic selenide $\pm \mathrm{Se}^{0}$ fraction, which is so large that an additional $8 \%$

363 would have very little effect on the calculated weighted mean. If so, loss of organic selenides

364 likely occurred during the treatment with $\mathrm{NaOH}$, which has been shown to mobilize organic

365 selenides from black shales and cherts of Cambrian age (Fan et al., 2011). As mentioned above, 
366 most of this labile organic $\mathrm{Se}^{-\mathrm{II}}$ fraction would have been lost during TCF filtration of the $\mathrm{NaOH}$

367 extract, unless it reacted with $\mathrm{O}_{2}$ dissolved in the $\mathrm{NaOH}$.

\section{5. Discussion}

The negative isotopic excursion in selenium isotopes associated with the latest Permian

371 extinction reaches values that are noticeably lighter than most previously reported measurements

372 from the sedimentary marine record (Johnson and Bullen, 2004; Mitchell et al., 2012; Rouxel et

373 al., 2002; Shore, 2010; Stüeken et al., 2015a; Stüeken et al., 2015b). Comparable values were

374 recently reported from very Se-rich samples (up to $116 \mathrm{ppm}$ ) of early Cambrian age that were

375 originally deposited under a ferruginous water column (Wen et al., 2014). As discussed in

376 Section 1, negative $\delta^{82 / 78}$ Se values are likely the result of non-quantitative Se oxyanion reduction

377 under locally suboxic conditions, i.e. in an environment that was connected to a large Se

378 oxyanion supply such as the oxygenated ocean. The short residence time of Se in seawater does

379 not allow us to extrapolate confidently from our sampling locality to the global ocean. However,

380 our data suggest that at least the Ishbel Trough experienced a brief interval around the latest

381 Permian extinction event during which (a) the supply of Se oxyanions exceeded the rate of

382 reduction, and (b) organic $\mathrm{Se}^{-\mathrm{III}}$ production was relatively minor compared to oxyanion $\mathrm{Se}$

383 reduction to inorganic phases. For at least this particular basin, this finding supports the

384 hypothesis that euxinia was not sufficiently widespread to draw down dissolved Se to low levels

385 throughout the extinction interval, and that biological productivity was only temporarily

386 depressed relative to Se supply. We interpret our data as a sequence of events represented by

387 stages I to IV as follows. 


\subsection{Stage I: high-productivity upwelling zone}

Stage I (Fig. 1), spanning the unconformity, is thought to have coincided with a period

391 during which regional coastal upwelling caused moderately high productivity and the

392 development of an oxygen minimum zone along the eastern margin of the Panthalassic ocean

393 (Georgiev et al., 2015; Henderson, 1997; Schoepfer et al., 2013; Schoepfer et al., 2012). Bulk

$394 \delta^{34} \mathrm{~S}$ is relatively high in stage I, indicative of minor diagenetic sulfate reduction within the

395 sediment as a closed system rather than in the open water column (Georgiev et al., 2015;

396 Schoepfer et al., 2013). However, enrichment in trace elements (including Mo, U, V) suggests

397 that the redox state of the water column was too reducing for efficient remineralization of

398 organic matter and thus probably suboxic (Schoepfer et al., 2013). Se in sediments should thus

399 include both organic $\mathrm{Se}^{-\mathrm{II}}$ as well as inorganic reduced phases produced from a continuous

400 supply of upwelled Se oxyanions. The organic fraction should be isotopically heavy, perhaps

401 similar to modern marine biomass (+0.3\%o, Mitchell et al., 2012), while the inorganic phases

402 should be significantly lighter, especially if upwelling continuously replenished Se oxyanions

403 and reduction was non-quantitative. Our results (averaging $-0.07 \pm 0.12 \%$, as described in

404 Section 4.1) are indeed consistent with a mixture of several Se phases with distinct isotopic

405 compositions, and they agree well with samples from the upwelling zone of the modern Arabian

406 Sea $(-0.07 \pm 0.16 \%$, Mitchell et al., 2012). A high local supply of Se oxyanions is further

407 indicated by Se/TOC ratios that are more than one order of magnitude greater than those in

408 modern phytoplankton (Fig. 6a). Se concentrations are also high relative to S (Fig. 6b),

409 suggesting that reduction of Se oxyanions was independent from sulfate reduction and proceeded

410 under suboxic conditions, perhaps concurrently with denitrification (Oremland, 1990), for which

411 there is evidence in these samples in the form of enriched nitrogen isotope ratios (Schoepfer et 
412 al., 2012). Our data are thus further evidence that Se does not behave as the geochemical twin of

413 S in the marine environment (Mitchell et al., 2012).

414 The sequential extraction experiment, which was conducted at the $-40 \mathrm{~cm}$ level from this

415 part of the section, confirms our interpretation of isotopic partitioning between inorganic and

416 organic reduced Se, and it also rules out the possibility that the Se in sediments of stage I is

417 purely detrital (cf. Georgiev et al., 2015). The Cr-reducible fraction (inorganic $\mathrm{Se}^{-\mathrm{II}} \pm \mathrm{Se}^{0} ;-0.90$

$418 \pm 0.46 \%$ ) is significantly lighter than the residual fraction (refractory organics $\pm \mathrm{Se}^{0} ;+0.03 \pm$

$4190.14 \%$ ). If we had been able to extract $\mathrm{Se}^{0}$ separately, the residual organic fraction would

420 probably be slightly heavier and capture more accurately the composition of marine biomass.

421 Inorganic reduced Se is evidently significantly depleted relative to organic $\mathrm{Se}^{-\mathrm{II}}$ and probably

422 relative to dissolved $\mathrm{Se}^{\mathrm{IV} / \mathrm{VI}}$, consistent with partial reduction of Se oxyanions.

423 The isotopically light $\mathrm{NaOH}$-soluble fraction (adsorbed $\mathrm{Se}^{\mathrm{IV}}$ or oxidized reduced phases;

$424-0.93 \pm 0.46 \%$ ) is probably not derived from $\mathrm{Se}^{\mathrm{IV}}$ dissolved in seawater; dissolved $\mathrm{Se}^{\mathrm{IV}}$ is

425 produced from organic matter remineralization (Cutter and Bruland, 1984), which does not

426 fractionate isotopes (Johnson et al., 1999). It should therefore be isotopically heavy. Instead, if it

427 is adsorbed $\mathrm{Se}^{\mathrm{IV}}$, then it is likely derived from $\mathrm{Se}^{\mathrm{VI}}$ reduction in sediments. In that case, the close

428 agreement between $\mathrm{Se}^{\mathrm{IV}}$ and inorganic $\mathrm{Se}^{-\mathrm{II}}$ and/or $\mathrm{Se}^{0}$ would suggest that $\mathrm{Se}^{\mathrm{VI}}$-to-Se ${ }^{\mathrm{IV}}$ reduction

429 was not quantitative, perhaps because it occurred close to the sediment-water interface, but

430 further reduction to $\mathrm{Se}^{0}$ or inorganic $\mathrm{Se}^{-\mathrm{II}}$, perhaps deeper in the sediments, was quantitative

431 (with the exception of the $\mathrm{Se}^{\mathrm{IV}}$ that was preserved by adsorption). Alternatively, the close match

432 between the $\mathrm{NaOH}$-extract and the $\mathrm{Cr}$-reducible fraction may indicate that the $\mathrm{NaOH}$ extraction

433 partially oxidized some inorganic reduced phases such as $\mathrm{Se}^{0}$ or $\mathrm{Se}^{-\mathrm{II}}$. Oxidation does not impart

434 significant isotopic fractionation (<0.5\% ,Johnson et al., 1999). 


\subsection{Stage II: euxinia}

The positive carbon isotope excursion during stage II (Fig. 1) likely marks a pulse in

438 productivity, perhaps due to increased nutrient input by volcanism or enhanced terrestrial

439 weathering (Georgiev et al., 2015; Schoepfer et al., 2013). It coincides with a massive pyrite bed,

440 which has been interpreted as mainly consisting of either diagenetic or hydrothermal

441 overgrowths on pre-existing pyrite framboids and organic particles (Schoepfer et al., 2013). Our

442 new analyses show that the pyrite bed is slightly depleted in $\delta^{34} \mathrm{~S}$ compared to stage I, which

443 would be consistent with a relatively higher contribution of syngenetic pyrite formed by

444 microbial sulfate reduction in the water column or at the sediment-water interface (Schoepfer et

445 al., 2013). The $\delta^{34} \mathrm{~S}$ values in the pyrite bed are however dissimilar to typical hydrothermal

446 pyrites (Seal, 2006). It is thus likely that stage II marks a brief interval during which increasing

447 biological productivity resulted in local bottom water euxinia and rapid precipitation of sulfide

448 minerals due to enhanced microbial sulfate reduction, both in the water column and under

449 diagenetic conditions (Georgiev et al., 2015). Widespread water-column euxinia may have

450 developed along continental margins shortly before the mass extinction event (Brennecka et al.,

451 2011), and the short interval of intense pyrite formation in this section is plausibly a local

452 manifestation of this phenomenon.

453 The positive excursion in $\delta^{82 / 78}$ Se to around $+0.5 \%$ during stage II is consistent with

454 locally anoxic conditions in which incoming Se oxyanions (either from weathering or upwelling)

455 were nearly quantitatively consumed by assimilation in the photic zone and/or by reduction

456 below, similar to modern anoxic basins (Cutter, 1982; Cutter, 1992). We speculate that a large

457 fraction of total Se in these samples is in the form of inorganic $\mathrm{Se}^{-\mathrm{II}}$ because of the high 
458 concentrations of both Se and S (Fig. 6b). Bulk sedimentary $\delta^{82 / 78}$ Se values may thus approach

459 the composition of seawater $\mathrm{Se}^{\mathrm{VI} / \mathrm{IV}}$ in the Ishbel Trough at this time. By mass balance the small

460 positive excursion in $\delta^{82 / 78}$ Se at this locality implies an isotopically light selenium sink

461 elsewhere. If euxinia was localized to oxygen minimum zones along continental margins (Algeo

462 et al., 2010; Brennecka et al., 2011; Proemse et al., 2013), then the isotopically light sink may

463 have been partial diagenetic reduction in deeper marine sediments further offshore in the Ishbel

464 Trough or even elsewhere in the ocean. To achieve an isotopic enrichment in residual dissolved

$465 \mathrm{Se}^{\mathrm{VI} / \mathrm{IV}}$ of $+0.5 \%$ by partial reduction, according to our fractionation model (Section 3.5 ) only

$4663.5 \%$ to $26 \%$ of the total $\mathrm{Se}^{\mathrm{VI} / \mathrm{IV}}$ reservoir needs to be reduced (which is $1-f$, expressed as a

467 percentage in the calculations, see Fig. 4). This relatively small fraction supports the hypothesis

468 that most of the deep ocean was oxic during this interval and that euxinia and the positive

469 excursion in $\delta^{82 / 78}$ Se were not global features (Algeo et al., 2010; Brennecka et al., 2011;

470 Proemse et al., 2013; Winguth and Maier-Reimer, 2005). The high Se/TOC ratios (Fig. 6a) also

471 support the conclusion that Se deposition was enhanced by local processes, because if euxinia

472 and Se drawdown had been an ocean-wide phenomenon, then the total marine Se reservoir

473 should have become so small that total concentrations at individual localities should have been

474 minimal. Our isotope and abundance data from stage II thus support the view that euxinia prior

475 to the mass extinction was not widespread or long-lived (Brennecka et al., 2011).

\section{5.3. Stage III: extinction}

478 Above the highly pyritic interval, $\delta^{13} \mathrm{C}$ decreases and $\delta^{15} \mathrm{~N}$ drops sharply from $+9 \%$ to

479 values around $+2 \%$ (Fig. 1), which has been interpreted as indicating the cessation of coastal

480 upwelling and a decline in productivity (Schoepfer et al., 2012). High TOC/S ratios, Fe 
481 speciation and the lack of trace metal enrichment are consistent with suboxic conditions in the 482 water column, i.e. somewhat more oxidized than in the preceding euxinic interval (Georgiev et 483 al., 2015; Schoepfer et al., 2013). The decline in $\delta^{34} \mathrm{~S}$ and the occurrence of framboidal pyrite 484 with diagenetic sulfide overgrowths and interstitial carbonate indicates that microbial sulfate 485 reduction occurred close to the sediment-water interface at a slower rate of sulfate consumption 486 than during stage II (Schoepfer et al., 2013). Hence sediments were probably suboxic to anoxic, 487 a process possibly accentuated by an increased sedimentation rate (Algeo and Twitchett, 2010). 488 Negative excursions in carbon and sulfur isotopes are observed globally at this time (Erwin et al., 489 2002; Fenton et al., 2007; Korte and Kozur, 2010; Korte et al., 2004; Newton et al., 2004; White, 490 2002), suggesting that this interval marks a worldwide perturbation in major biogeochemical 491 cycles.

493 than most marine sediments (Mitchell et al., 2012; Stüeken et al., 2015a; Stüeken et al., 2015b;

494 Wen et al., 2014). It is unlikely that this excursion reflects volcanic input of Se from the Siberian 495 Traps (Campbell et al., 1992) or enhanced weathering due to vegetation loss on land (Georgiev 496 et al., 2015; Ward et al., 2000) because both of those sources would have had a Se isotopic 497 composition near the crustal average of 0\%. Although one study of unusually Se-rich rocks (up 498 to $26,000 \mathrm{ppm}$ ) showed large fractionations of several permil during weathering (Zhu et al., 499 2014), fractionations were minimal $( \pm 0.25 \%$ ) in a Se-poor soil (up to $0.5 \mathrm{ppm}$, Schilling et al., 500 2011) which is more representative of average crust (0.09 ppm, Rudnick and Gao, 2014). Hence 501 a pulse of continental weathering probably did not cause the large negative excursion observed in 502 stage III. The only other type of geological samples known to be isotopically depleted by $2 \%$ or 503 more relative to the crust are hydrothermal precipitates and supergene alteration products 
504 (Layton-Matthews et al., 2013; Rouxel et al., 2004; Wen and Carignan, 2011; Zhu et al., 2014).

505 However, it is unlikely that enhanced hydrothermal fluid input or erosion of hydrothermal

506 deposits caused this excursion because other elements such as $\mathrm{Cu}$, with short ocean residence

507 times and commonly associated with hydrothermal activity, are close to crustal background

508 levels during stage III and into stage IV (Schoepfer et al., 2013). Post-depositional supergene

509 alteration (Wen and Carignan, 2011; Zhu et al., 2014) can be ruled out because the selenium

510 isotope excursion correlates well with global excursions in $\delta^{34} \mathrm{~S}$ and $\delta^{13} \mathrm{C}$, and because below a

511 weathering rind, which was removed during sample preparation, pyrite is well preserved without

512 any sign of oxidation (see also Georgiev et al., 2015). Se input from weathering of altered rocks

513 elsewhere (cf. Zhu et al., 2014) is improbable because then similarly light values should be

514 common throughout Earth's history (cf .Mitchell et al., 2012; Stüeken et al., 2015b) and should

515 not correlate with seawater redox conditions (cf. Wen et al., 2014). The most plausible

516 explanation for a negative excursion of this magnitude in marine sediments is thus partial

517 reduction of Se oxyanions to $\mathrm{Se}^{0}$ and/or inorganic $\mathrm{Se}^{-\mathrm{II}}$ at the site of deposition.

$518 \quad$ Preservation of $\delta^{82 / 78}$ Se values significantly below the crustal average can only occur if

519 dissolved Se oxyanions are not quantitatively consumed, i.e. if there was a stable Se oxyanion

520 reservoir in the water column. Given the uncertainty in natural fractionation factors, the amount

521 of reduction required to explain a value of $-1.8 \%$ may be anywhere between $9 \%$ and $96 \%$ of the

522 oceanic $\mathrm{Se}^{\mathrm{VI} / \mathrm{IV}}$ reservoir according to our fractionation model (Fig. 4). But if the fractionation

523 factor was small (Fig. 4a,c), i.e. close to the range of $\delta^{82 / 78}$ Se values observed in marine

524 sediments, a smaller percentage is more likely. If so, then this implies that the water column

525 must have been sufficiently oxygenated for residual dissolved $\mathrm{Se}^{\mathrm{VI} / \mathrm{V}}$ concentrations to exceed

526 biological demand, which may also explain the relatively high Se/TOC ratios during the 
527 excursion interval (Fig. 6a). Anoxia or suboxia probably only existed locally in bottom waters

528 (Georgiev et al., 2015), such that partial $\mathrm{Se}^{\mathrm{IV} / \mathrm{VI}}$ reduction and preservation of $\mathrm{Se}^{0}$ and/or $\mathrm{Se}^{-\mathrm{II}}$

529 were thermodynamically favored. This interpretation is consistent with other geochemical

530 evidence indicating widespread (sub-)oxic conditions in the open ocean across the extinction

531 event (Algeo et al., 2010; Brennecka et al., 2011; Proemse et al., 2013). Although our data

532 represent only one basin, it is thus possible that Se oxyanions were stable throughout most the

533 ocean at this time and were not removed by euxinia. Sulfur concentrations are not particularly

534 high during this interval (Fig. 6b), so Se oxyanion reduction probably occurred independently

535 from sulfate reduction, as in stage I, perhaps at the oxic-suboxic interface in sediments or in

536 bottom waters.

537 By comparison, a smaller negative isotope excursion down to $-0.63 \%$ o has been reported

538 for the late Cretaceous Ocean Anoxic Event 2 when volcanic activity may have increased the

539 supply of nutrients, including selenium (Mitchell et al., 2012). That report (Mitchell et al., 2012)

540 argued that high nutrient input stimulated productivity, but that Se oxyanions were supplied in

541 amounts beyond the capacity for complete biological reduction. In the Opal Creek section,

542 however, productivity evidently declined during stage III (Schoepfer et al., 2013; Schoepfer et

543 al., 2012), trace metals are not enriched with respect to crustal compositions (Schoepfer et al.,

544 2013) and TOC concentrations are 1-2 orders of magnitude lower than in the late Cretaceous

545 excursion (Mitchell et al., 2012). It is thus more likely that at Opal Creek dissolved Se ${ }^{\mathrm{VI} / \mathrm{IV}}$ excess

546 resulted not from a high Se supply but instead from a relatively low demand.

547 Because biological assimilation and reduction are the major sinks of Se from the ocean,

548 this decrease in the consumption rate could indicate a decline in organic Se export from the

549 surface ocean to the sediments. Thus, Se isotopes were possibly sensitive, at least locally, to the 
550 collapse in productivity by macroscopic organisms associated with the latest Permian mass

551 extinction. Assuming a small isotopic fractionation factor between 2 and 2.5\%, the isotopic

552 composition of residual dissolved $\mathrm{Se}^{\mathrm{VI}}$ during the peak of the negative $\delta^{82 / 78} \mathrm{Se}$ excursion would

553 have been between $+0.2 \%$ and $+1.6 \%$, depending on whether partial reduction occurred under

554 open- or closed-system conditions (Section 3.5). The complementary sink of this isotopically

555 enriched dissolved Se may have been in restricted basins or in localized euxinic parts of the

556 ocean (Algeo et al., 2010; Brennecka et al., 2011).

557 The slight offset between the minimum in $\delta^{82 / 78} \mathrm{Se}$ and the major paleontological

558 extinction horizon defined by conodont turnover and the disappearance of sponge spicules and

559 bioturbation (Schoepfer et al., 2012) is perhaps due to weakened upwelling that led to a local

560 decrease in the dissolved Se oxyanion supply. Consequently, Se reduction or assimilation may

561 have become more quantitative, resulting in less negative $\delta^{82 / 7}$ Se values even when biological

562 productivity was very low. If so, then the extinction at this site was perhaps influenced by a

563 limiting supply of nutrients, including Se. Alternatively, it is possible that total macroscopic

564 productivity was indeed at its minimum prior to the extinction peak due to reasons other than

565 nutrient supply, but microbial productivity resumed quickly (e.g. Algeo et al., 2011; Georgiev et

566 al., 2015; Shen et al., 2014) and already dominated Se consumption and export by the time major

567 groups of metazoans died out. However, Se/TOC ratios decline steadily throughout stage III

568 (Table 2), supporting the first scenario of dwindling Se input. In either case, our data suggest that

569 locally, and perhaps over a wider area, total biological productivity collapsed over the course of

$570 \sim 1 \mathrm{kyr}$ (from $\sim 10 \mathrm{~cm}$ to $12 \mathrm{~cm}$, assuming the sedimentation rate of $0.5 \mathrm{kyr} \mathrm{cm}^{-1}$ (Farley et al.,

$5712005)$ ) under relatively oxygenated conditions. 


\subsection{Stage IV: recovery}

574

575

576

577

578

579

580

581

582

583

584

585

586

587

588

589

590

591

592

593

594

595

During stage IV (Fig. 1), sulfur and carbon isotopes in the Ishbel Trough change little compared to the end of stage III, indicating that the ocean probably continued to be oxic to suboxic and productivity remained low (Georgiev et al., 2015; Schoepfer et al., 2012). Bottomwater suboxia and rapid burial likely limited organic matter re-oxidation, leading to the high TOC content of these samples.

$\delta^{82 / 78} \mathrm{Se}$ is the only tracer that returns to values similar to stage I (average $-0.05 \pm 0.42 \%$, $\mathrm{n}=14$, Fig. 1), probably because Se is a much rarer element than $\mathrm{C}$ and $\mathrm{S}$ with a shorter residence time in the ocean and so is perhaps more sensitive to environmental changes and ocean circulation. The return to slightly heavier values could have resulted from two processes: (i) consumption of a relatively higher proportion of Se oxyanions by partial reduction than during stage III, leading to a smaller net fractionation in the reduced phase compared to the starting composition (as modeled in Fig. 4 for large values of $f$ ), or (ii) isotopically heavy organic $\mathrm{Se}^{-\mathrm{II}}$ becoming the major component in marine sediments, leading to dilution of isotopically light $\mathrm{Se}^{0}$ and/or inorganic $\mathrm{Se}^{-\mathrm{II}}$ produced from oxyanion reduction. Both processes would have been facilitated by a lower supply of Se oxyanions to the shelf, i.e. through continued suppression of coastal upwelling, but also by local recovery of biological activity. The first possibility is supported by Se/TOC ratios, which are distinctly lower in stage IV than in other parts of the section (Fig. 6a). Hence low nutrient supply under oxic to suboxic conditions perhaps continued to delay biological recovery into the early Triassic.

Combined with data from stage III, we observe an inverse relationship between $\delta^{82 / 78} \mathrm{Se}$ values and the logarithm of Se/TOC ratios $\left(\mathrm{R}^{2}=0.57\right)$. Low Se/TOC ratios paired with high $\delta^{82 / 78}$ Se values may reflect a situation in which the supply of Se was locally limited and only 
596 organic $\mathrm{Se}^{-\mathrm{II}}$ was preserved; high Se/TOC ratios paired with low $\delta^{82 / 78}$ Se values likely indicate 597 increased availability of Se oxyanions, which were then subject to partial reduction. If the sample 598 with highest $\delta^{82 / 78} \mathrm{Se}$ and lowest Se/TOC (Fig. 6a, circle A) represents nearly pure biomass with 599 no addition of $\mathrm{Se}^{0}$ and/or inorganic $\mathrm{Se}^{-\mathrm{II}}$ to the sediment, then it may capture the composition of 600 seawater $\mathrm{Se}^{\mathrm{VI}}$ in the early Triassic.

601 During stage IV, the $\delta^{82 / 78}$ Se record returns to values typical of Stage I, diverging 602 markedly from the $\delta^{34} \mathrm{~S}$ record which shows a comparatively small recovery (Fig. 1). The sulfur 603 system is only sensitive to profound redox changes, which, as discussed above and elsewhere 604 (Algeo et al., 2010; Proemse et al., 2013; Schoepfer et al., 2012), did not occur between the onset 605 of the extinction (stage III) and the subsequent recovery. Even though the dissolved sulfate 606 reservoir may have contracted (Luo et al., 2010), sulfate was likely a conservative ion before, 607 during and after the latest Permian extinction event. Se, however, being a trace element in the 608 ocean, is more sensitive to subtle and local redox and productivity changes. In this case, our Se 609 data indicate more clearly than the S record alone that ocean circulation was sluggish, though not 610 absent, across the Permian-Triassic boundary.

\section{6. Conclusion}

613 At Opal Creek, Se isotopes display a large negative excursion in marine sediments, 614 slightly before the largest mass extinction of the Phanerozoic eon. We proposed that these low $615 \delta^{82 / 78}$ Se values in bulk sediments resulted from a unique decline of macro-biological activity and 616 organic Se export, leading to excess Se oxyanion concentrations in the water column, which

617 were then subject to partial reduction in suboxic bottom waters or at the sediment-water 618 interface. The event is preceded by a small positive excursion, which was likely caused by 
619 locally euxinic conditions due to a temporary increase in productivity, and hence quantitative

620 consumption of isotopically heavy Se in the water column. However, euxinia was likely limited

621 to continental margins, consistent with recent evidence from Mo and $\mathrm{U}$ isotopes and metal

622 abundances (Algeo et al., 2010; Algeo et al., 2011; Brennecka et al., 2011; Proemse et al.,

623 2013), and thus probably not responsible for the mass extinction. Instead, our data suggest that at

624 least this basin was oxic at the onset of the productivity decline, because otherwise Se oxyanions

625 would not have been stable in the water column. Although we can only confidently speak for this

626 one locality, our data support models of oxic conditions in the open Panthalassic ocean at the

627 time of the mass extinction (e.g. Winguth and Maier-Reimer, 2005). Productivity during the

628 extinction appears to have collapsed quickly over $\sim 1$ kyr. During the peak extinction in the latest

629 Permian and continuing into the early Triassic, an increasingly stratified ocean (Song et al.,

630 2013) decreased the supply of nutrients to the surface, leading to more quantitative Se

631 consumption even under oxic to suboxic conditions. Hence nutrient limitation probably did not

632 cause the initial collapse of the marine biosphere but it may have inhibited its recovery.

633 Lastly, this study shows that Se isotopes can be a valuable proxy for geobiological

634 changes in deep time. As demonstrated with one sample, the sequential extraction and isotopic

635 analysis of different Se phases may help disentangle some of the complexity of this new isotopic 636 system and should be pursued in future studies.

638 Acknowledgements 
642 Royalty Research Fund grant to RB. We thank Joy Laydbak and Scott Kuehner for technical

643 support as well as the editor and three anonymous reviewers for constructive criticism. 
644 Table 1: Method comparison. Selenium isotope results, given in \%o, for four samples processed 645 with two different protocols (D) and (E). $\mathrm{M}=$ number of replicate analyses. Differences between 646 protocols are not systematic.

647

\begin{tabular}{|c|c|c|c|c|c|c|c|c|c|c|c|c|c|c|}
\hline \multirow[b]{2}{*}[\mathrm{cm}]{} & \multicolumn{7}{|c|}{ Method D } & \multicolumn{7}{|c|}{ Method E } \\
\hline & M & $\delta^{82 / 78} \mathrm{Se}$ & $2 \sigma$ & $\delta^{76 / 78} \mathrm{Se}$ & $2 \sigma$ & $\delta^{77 / 78} \mathrm{Se}$ & $2 \sigma$ & $\mathbf{M}$ & $\delta^{82 / 78} \mathrm{Se}$ & $2 \sigma$ & $\delta^{76 / 78} \mathrm{Se}$ & $2 \sigma$ & $\delta^{77 / 78} \mathrm{Se}$ & $2 \sigma$ \\
\hline-4 & 5 & -0.05 & 0.58 & -0.04 & 0.32 & 0.05 & 0.24 & 4 & -0.01 & 0.26 & -0.01 & 0.22 & 0.01 & 0.08 \\
\hline 22 & 8 & -1.95 & 0.58 & 0.93 & 0.34 & 0.55 & 0.26 & 4 & -1.58 & 0.10 & 0.84 & 0.48 & 0.43 & 0.02 \\
\hline 49.5 & 2 & -0.32 & 0.28 & 0.39 & 0.08 & 0.37 & 0.42 & 4 & -0.60 & 0.14 & 0.37 & 0.34 & 0.18 & 0.04 \\
\hline 159.5 & 3 & -0.06 & 0.30 & -0.77 & 1.20 & -0.12 & 0.32 & 4 & -0.08 & 0.20 & 0.04 & 0.08 & 0.09 & 0.08 \\
\hline
\end{tabular}

648

649

650

651 
Table 2: Data set. $\mathrm{M}(\mathrm{Se})=$ number of replicate Se measurements, using method D in Stüeken et al. (2013) unless noted otherwise in column $1 ; \mathrm{RE}=$ relative error; blank = not determined; dashed lines = stages boundaries discussed in the text. While $\delta^{82 / 78} \mathrm{Se}, \delta^{77 / 78} \mathrm{Se}$ and $\delta^{76 / 78} \mathrm{Se}$ were directly measured, $\delta^{82 / 76} \mathrm{Se}$ was calculated from $\delta^{82 / 78} \mathrm{Se}$ by multiplication with a factor of 1.54 to facilitate

comparison of our data with other recent studies. C and S data are from Schoepfer et al. $(2013 ; 2012)$ unless listed in Section 3.4.

\begin{tabular}{|c|c|c|c|c|c|c|c|c|c|c|c|c|c|c|c|c|c|}
\hline $\begin{array}{l}\text { depth } \\
{[\mathrm{cm}]}\end{array}$ & $\begin{array}{c}\text { M } \\
(\mathrm{Se})\end{array}$ & $\begin{array}{c}\text { Se } \\
{[\mathrm{ppm}]}\end{array}$ & $\begin{array}{l}\text { RE } \\
{[\%]}\end{array}$ & $\begin{array}{c}\delta^{82 / 78} \mathrm{Se} \\
{[\% 0]}\end{array}$ & $\begin{array}{l}2 \sigma \\
{[\% o]}\end{array}$ & $\begin{array}{c}\delta^{82 / 76} \mathrm{Se} \\
{[\% 0]}\end{array}$ & $\begin{array}{c}2 \sigma \\
{[\% o]}\end{array}$ & $\begin{array}{c}\delta^{76 / 78} \mathrm{Se} \\
{[\% 0]}\end{array}$ & $\begin{array}{c}2 \sigma \\
{[\%,]}\end{array}$ & $\begin{array}{c}\delta^{777 / 78} \mathrm{Se} \\
{[\% \text { ] }]}\end{array}$ & $\begin{array}{c}2 \sigma \\
{[\% o]}\end{array}$ & $\begin{array}{c}\mathbf{S} \\
{[\%]}\end{array}$ & $\begin{array}{l}\delta^{34} S \\
{[\% \circ]}\end{array}$ & $\begin{array}{l}\text { TOC } \\
{[\%]}\end{array}$ & $\begin{array}{l}\delta^{13} \mathrm{C} \\
{[\% \text { o] }}\end{array}$ & $\begin{array}{l}\log (\mathrm{Se} / \mathrm{S}) \\
{[\mathrm{mol} / \mathrm{mol}]}\end{array}$ & $\begin{array}{c}\log (\mathrm{Se} / \mathrm{TOC}) \\
{[\mathrm{mol} / \mathrm{mol}]}\end{array}$ \\
\hline-40 & 9 & 9.61 & 2.91 & -0.17 & 0.22 & -0.26 & 0.33 & 0.06 & 0.13 & 0.07 & 0.20 & 0.65 & -2.90 & 0.52 & -29.77 & -3.22 & -3.55 \\
\hline-21 & 7 & 25.08 & 17.39 & -0.09 & 0.51 & -0.14 & 0.78 & 0.02 & 0.22 & 0.00 & 0.13 & 0.86 & -1.27 & 0.95 & -29.66 & -2.93 & -3.40 \\
\hline-4 (a) & 9 & 8.49 & 4.63 & -0.03 & 0.45 & -0.05 & 0.69 & -0.03 & 0.27 & 0.03 & 0.18 & 0.86 & 0.63 & 0.36 & -28.90 & -3.39 & -3.45 \\
\hline $1.5(\mathrm{~b})$ & 3 & 9.40 & 1.35 & 0.68 & 0.26 & 1.04 & 0.40 & -0.35 & 0.22 & -0.15 & 0.07 & 1.74 & -2.73 & 1.29 & -29.68 & -3.66 & -3.95 \\
\hline 3 & 2 & 8.52 & 4.07 & 0.00 & 0.02 & -0.01 & 0.03 & -0.09 & 0.03 & 0.11 & 0.32 & 4.37 & -11.06 & 0.08 & -27.00 & -4.10 & -2.80 \\
\hline 3.5 (b) & 3 & 12.50 & 1.79 & -0.06 & 0.19 & -0.09 & 0.29 & 0.05 & 0.11 & 0.02 & 0.04 & 3.47 & -7.47 & 1.24 & -29.75 & -3.84 & -3.82 \\
\hline 4 & 2 & $24.42^{\circ}$ & $5.90^{\circ}$ & 0.60 & 0.03 & 0.92 & 0.05 & -0.24 & 0.02 & -0.11 & 0.13 & 29.87 & -8.99 & 0.13 & -27.05 & -4.48 & -2.53 \\
\hline 5 & 2 & 25.56 & 31.64 & 0.59 & 0.31 & 0.91 & 0.48 & -0.33 & 0.13 & -0.24 & 0.52 & 28.71 & -7.73 & 0.12 & -27.44 & -4.44 & -2.48 \\
\hline 6 & 2 & 18.56 & 52.70 & 0.70 & 0.46 & 1.08 & 0.71 & -0.31 & 0.07 & -0.01 & 0.60 & 9.32 & -8.48 & 0.32 & -29.65 & -4.09 & -3.05 \\
\hline 8 & 2 & 22.88 & 6.28 & 0.67 & 0.06 & 1.03 & 0.09 & -0.35 & 0.07 & -0.17 & 0.15 & 27.86 & -8.38 & 0.12 & -26.38 & -4.48 & -2.53 \\
\hline 9 & 2 & 18.49 & 2.54 & 0.19 & 0.30 & 0.29 & 0.45 & -0.16 & 0.14 & 0.01 & 0.09 & 26.35 & -7.34 & 0.21 & -25.68 & -4.55 & -2.87 \\
\hline 10.5 & 7 & 8.31 & 3.96 & -0.41 & 0.65 & -0.63 & 1.00 & 0.16 & 0.28 & 0.10 & 0.25 & 5.77 & -11.85 & 0.10 & -25.77 & -4.23 & -2.88 \\
\hline 15 & 4 & 4.35 & 7.61 & -1.08 & 0.53 & -1.66 & 0.82 & 0.52 & 0.32 & 0.26 & 0.26 & 1.76 & -7.30 & 0.07 & -26.69 & -4.00 & -3.02 \\
\hline $17.5(b)$ & 2 & 3.94 & 0.22 & -1.54 & 0.12 & -2.37 & 0.19 & 0.82 & 0.06 & 0.39 & 0.03 & 2.58 & -17.73 & 0.08 & -27.16 & -4.21 & -3.11 \\
\hline 22 (a) & 12 & 2.31 & 10.98 & -1.83 & 0.59 & -2.81 & 0.91 & 0.90 & 0.39 & 0.51 & 0.24 & 2.96 & -19.52 & 0.10 & -27.06 & -4.50 & -3.46 \\
\hline 24.25 (b) & 2 & 2.30 & 0.47 & -1.74 & 0.05 & -2.68 & 0.07 & 0.95 & 0.02 & 0.48 & 0.02 & 2.67 & -21.50 & 0.00 & & -4.46 & \\
\hline 29 & 5 & 2.06 & 5.61 & -1.53 & 0.71 & -2.36 & 1.10 & 1.10 & 0.32 & 0.38 & 0.25 & 5.36 & -30.90 & 0.29 & -29.59 & -4.81 & -3.97 \\
\hline 30.75 & 8 & 2.46 & 13.10 & -1.22 & 0.35 & -1.88 & 0.54 & 0.84 & 0.22 & 0.40 & 0.18 & 3.74 & -23.99 & 0.46 & -30.76 & -4.57 & -4.09 \\
\hline $36.5(b)$ & 2 & 2.48 & 0.19 & -1.08 & 0.05 & -1.67 & 0.08 & 0.58 & 0.07 & 0.32 & 0.00 & 2.57 & -23.34 & 0.62 & -29.73 & -4.41 & -4.21 \\
\hline $37.5(b)$ & 2 & 2.39 & 8.06 & -1.06 & 0.12 & -1.63 & 0.18 & 0.59 & 0.01 & 0.37 & 0.07 & 3.93 & -19.00 & 0.39 & -30.37 & -4.61 & -4.03 \\
\hline 40 (b) & 2 & 2.82 & 0.57 & -0.79 & 0.25 & -1.22 & 0.38 & 0.43 & 0.13 & 0.26 & 0.09 & & -22.59 & 0.48 & -30.96 & & -4.04 \\
\hline 43 & 2 & 5.14 & 6.67 & -0.52 & 0.25 & -0.81 & 0.39 & 0.39 & 0.03 & 0.21 & 0.24 & 3.55 & -23.58 & 0.66 & -30.55 & -4.23 & -3.93 \\
\hline 46 (b) & 2 & 3.19 & 0.48 & -1.28 & 0.12 & -1.98 & 0.19 & 0.71 & 0.00 & 0.40 & 0.02 & & & 0.89 & -30.92 & & -4.27 \\
\hline 49.5 (a) & 6 & 2.53 & $4.22^{-}$ & -0.51 & 0.33 & -0.78 & 0.51 & 0.38 & 0.26 & 0.25 & 0.27 & 2.60 & -25.96 & 0.40 & -31.34 & -4.40 & -4.01 \\
\hline 72 & 2 & 2.26 & 1.18 & -0.54 & 0.26 & -0.84 & 0.40 & 0.38 & 0.14 & 0.31 & 0.21 & 3.31 & -19.43 & 0.70 & -31.04 & -4.56 & -4.31 \\
\hline 90.15 & 5 & 1.64 & 5.47 & -0.51 & 0.46 & -0.78 & 0.71 & 0.56 & 0.14 & 0.26 & 0.23 & 3.54 & -19.99 & 0.75 & -31.16 & -4.73 & -4.48 \\
\hline 106.25 & 5 & 1.35 & 4.08 & -0.57 & 0.50 & -0.88 & 0.77 & 0.31 & 0.25 & 0.29 & 0.19 & 2.80 & -19.52 & 1.01 & -30.70 & -4.71 & -4.69 \\
\hline 116.75 & 4 & 1.16 & 8.45 & -0.35 & 0.87 & -0.53 & 1.34 & 0.29 & 0.40 & 0.18 & 0.28 & 3.35 & -16.77 & 1.45 & -30.49 & -4.85 & -4.91 \\
\hline 133.5 & 5 & 1.72 & 2.23 & -0.19 & 0.39 & -0.29 & 0.60 & 0.13 & 0.18 & 0.11 & 0.25 & 2.65 & -20.59 & 1.97 & -31.64 & -4.58 & -4.88 \\
\hline 159.5 (a) & 6 & 0.58 & 7.08 & -0.17 & 0.35 & -0.27 & 0.54 & 0.10 & 0.19 & 0.10 & 0.07 & 3.63 & -9.79 & 0.62 & -31.97 & -5.19 & -4.85 \\
\hline 310.5 & 3 & 0.58 & 4.02 & -0.02 & 0.44 & -0.04 & 0.68 & & 0.00 & 0.17 & 0.34 & 1.89 & -20.41 & 1.57 & -31.62 & -4.90 & -5.25 \\
\hline 386 & 5 & 0.90 & 4.36 & 0.59 & 0.56 & 0.90 & 0.87 & -0.26 & 0.61 & 0.00 & 0.26 & 1.88 & -20.42 & 1.66 & -32.06 & -4.71 & -5.08 \\
\hline 494.2 & 3 & 1.17 & 2.09 & 0.35 & 0.27 & 0.55 & 0.42 & -0.21 & 0.12 & -0.10 & 0.12 & 3.09 & -13.70 & 2.01 & -31.92 & -4.81 & -5.05 \\
\hline 563 & 3 & 0.92 & 5.65 & 0.49 & 0.18 & 0.76 & 0.28 & -0.32 & 0.86 & 0.17 & 0.45 & 1.62 & -20.03 & 2.30 & -31.90 & -4.64 & -5.22 \\
\hline 850.5 & 4 & 1.35 & 6.53 & 0.35 & 0.39 & 0.54 & 0.59 & -0.41 & 0.28 & 0.02 & 0.17 & 1.96 & -10.89 & 2.26 & -31.57 & -4.55 & -5.04 \\
\hline 1237 & 2 & 0.96 & 1.82 & -0.11 & 0.18 & -0.16 & 0.28 & -0.35 & 0.05 & 0.09 & 0.04 & 1.47 & -14.30 & 2.14 & -30.97 & -4.58 & -5.16 \\
\hline 1684 & 2 & 0.58 & 7.80 & 0.35 & 0.34 & 0.54 & 0.52 & -0.63 & 0.67 & 0.18 & 0.22 & 1.25 & -18.25 & 1.62 & -30.57 & -4.72 & -5.26 \\
\hline
\end{tabular}

(a) Prepared with both protocols D and E in Stüeken et al. (2013). See Table 1 for method comparison. 
668

669
Table 3: Selenium species in sample from $\mathbf{- 4 0} \mathbf{~ c m}$. Isotopic values are given in \%o, selenium concentrations in ppm. \% tot. $=$ fraction of bulk rock. Each fraction was prepared and analyzed in four replicates. SeX = uncertain contributions of reduced Se phases that were oxidized by $\mathrm{O}_{2}$ dissolved in $\mathrm{NaOH}$. Reported errors for the three extracts are the standard deviations of the four replicates for each extraction step. Errors for the weighted average are propagated. As in Table 2, values for $\delta^{82 / 76} \mathrm{Se}$ were calculated from $\delta^{82 / 78} \mathrm{Se}$ whereas all others were measured directly.

\begin{tabular}{|c|c|c|c|c|c|c|c|c|c|c|c|c|c|}
\hline reagent & Se species & [Se] & $2 \sigma$ & $\begin{array}{c}\% \\
\text { tot. }\end{array}$ & $2 \sigma$ & $\delta^{82 / 78} \mathrm{Se}$ & $2 \sigma$ & $\delta^{82 / 76} \mathrm{Se}$ & $2 \sigma$ & $\delta^{76 / 78} \mathrm{Se}$ & $2 \sigma$ & $\delta^{77 / 78} \mathrm{Se}$ & $2 \sigma$ \\
\hline $\mathrm{NaOH}$ & $\mathrm{Se}^{\mathrm{IV}}{ }_{\text {ads }} \pm \mathrm{SeX}$ & 0.62 & 0.04 & $6.4 \%$ & $0.4 \%$ & -0.93 & 0.46 & -1.44 & 0.36 & 0.47 & 0.24 & 0.29 & 0.48 \\
\hline $\mathrm{CrCl}_{2}+\mathrm{HCl}$ & $\mathrm{Se}_{\mathrm{pyr}}^{-\mathrm{II}} \pm \mathrm{Se}^{0}$ & 1.26 & 0.34 & $13.2 \%$ & $3.4 \%$ & -0.90 & 0.46 & -1.39 & 0.36 & 0.47 & 0.28 & 0.20 & 0.30 \\
\hline $\mathrm{HF}+\mathrm{HClO}_{4}+\mathrm{HNO}_{3}$ & $\mathrm{Se}^{-\mathrm{II}_{\text {org }}} \pm \mathrm{Se}^{0}$ & 6.93 & 1.26 & $72.2 \%$ & $13.0 \%$ & 0.03 & 0.14 & 0.04 & 0.11 & -0.08 & 0.12 & 0.05 & 0.38 \\
\hline weighted average & & 8.82 & 1.84 & $91.7 \%$ & $9.4 \%$ & -0.16 & 0.12 & -0.24 & 0.16 & 0.04 & 0.10 & 0.08 & 0.28 \\
\hline missing & & & & $8.3 \%$ & $9.4 \%$ & & & & & & & & \\
\hline
\end{tabular}


672 Figure 1: Stratigraphic section across the PT extinction event in the Western Canada Basin

673 at Opal Creek. Sulfur data are from Schoepfer et al. (2013); carbon and nitrogen data and

674 lithostratigraphy are from Schoepfer et al. (2012). Triangles $=$ chert, broken lines $=$ siltstone,

675 solid lines $=$ shale, dotted black line $=$ unconformity, PYR and yellow bar $=$ pyrite-rich bed

676 (based on TS concentrations in Table 1; its usage here does not correspond exactly with its usage

677 by Schoepfer et al. (2013; 2012), because our sampling density is higher during this interval),

678 EXT and dashed red line $=$ main extinction horizon, PTB and solid green line $=$ Permian-Triassic

679 boundary. $\delta^{82 / 78}$ Se data show 2-sigma error bars. Roman numerals refer to stages described in the

680 text. A: complete section. B: detail of the section between -0.5 and $+1.0 \mathrm{~m}$.

681

682 Figure 2: Sequential extraction protocol. Solid arrows mark transfer of rock powder; dashed 683 arrows mark separation and removal of selenium species from rock powder. See Section 3.2 for 684 detailed descriptions of each step.

685

Figure 3: Mass-dependent fractionation and interference correction. Empty diamonds are

687 individual measurements, filled diamonds are averages $\pm 2 \sigma$ (Table 2). a: $\delta^{77 / 78}$ Se versus $\delta^{82 / 78}$ Se.

688 b: $\delta^{76 / 78}$ Se versus $\delta^{82 / 78}$ Se. Line marks the theoretical relationship of mass-dependent

689 fractionation. Within $2 \sigma$, almost all samples fall along the mass-dependent fractionation line,

690 indicating that natural mass-independent mass fractionation is absent and that major isobaric

691 interferences have been adequately corrected.

692 
693 Figure 4: Possible solutions for Se isotope mass balance. a, b: Open system fractionation with

694 a maximum fractionation of $\varepsilon=2 \%$ (a) or $14 \%$ (b). c, d: Closed system Rayleigh fractionation

695 with a maximum fractionation of $\varepsilon=2 \%$ (c) or $14 \%$ (d). Dashed arrows point to values of $f$

696 needed to obtain $\delta^{82 / 78} \mathrm{Se}^{\mathrm{VI} / \mathrm{IV}}=+0.5 \%$, dotted arrows point to values of $f$ needed to obtain

$697 \delta^{82 / 78} \mathrm{Se}^{\text {red }}=-1.8 \%$. Model calculations are explained in Section 3.5.

698

699 Figure 5: Sequential extraction of Se phases in sample $\mathbf{- 4 0} \mathbf{~ c m}$. a: isotopic compositions. Blue

700 diamond $=$ adsorbed $\mathrm{Se}^{\mathrm{IV}}$ with potential traces of reduced Se phases $(\mathrm{SeX})$ oxidized by $\mathrm{O}_{2}$

701 dissolved in $\mathrm{NaOH}$; yellow square $=$ inorganic $\mathrm{Se}^{-\mathrm{II}} \pm \mathrm{Se}^{0}$; brown triangle $=$ refractory organic

$702 \mathrm{Se}^{-\mathrm{II}} \pm \mathrm{Se}^{0}$; black circle $=$ bulk sample; red $\mathrm{x}=$ weighted average of extracted fractions; solid line

$703=$ theoretical mass-dependent fractionation line. b: Relative proportions of Se phases in bulk

704 sample, using the same color scheme as in panel a. nd = not determined (missing fraction). All

705 errors are $2 \sigma$ and listed in Table 3.

706

707 Figure 6: $\boldsymbol{\delta}^{\mathbf{8 2 / 7 8}}$ Se versus Se/TOC (a) and total Se versus total S (b). In panel a, green bar 708 marks Se/TOC ratio of modern phytoplankton $\left(1.7 \cdot 10^{-6}\right.$ to $5.7 \cdot 10^{-6}$, Mitchell et al., 2012). A: a

709 circle that represents the range for a putative biomass end-member that may capture the isotopic

710 composition of early Triassic seawater. B: Effects of Se addition to sediments by reductive

711 scavenging in oxygen-minimum zone (stage I) or local euxinia (stage II). C: Effects of Se

712 addition by partial (diagenetic) reduction in suboxic bottom water or sediment (stages III and

713 IV). 


\section{References}

Algeo, T.J., Henderson, C.M., Tong, J., Feng, Q., Yin, H. and Tyson, R.V., 2013. Plankton and productivity during the Permian-Triassic boundary crisis: An analysis of organic carbon fluxes. Global and Planetary Change, 105: 52-67.

Algeo, T.J., Hinnov, L., Moser, J., Maynard, B., Elswick, E., Kuwahara, K. and Sano, H., 2010. Changes in productivity and redox conditions in the Panthalassic Ocean during the latest Permian. Geology, 38: 187-190.

Algeo, T.J., Kuwahara, K., Sano, H., Bates, S., Lyons, T.W., Elswick, E., Hinnov, L., Ellwood, B., Moser, J. and Maynard, B., 2011. Spatial variation in sediment fluxes, redox conditions, and productivity in the Permian-Triassic Panthalassic Ocean. Palaeogeography, Palaeoclimatology, Palaeoecology, 308(1-2): 65-83.

Algeo, T.J. and Tribovillard, N., 2009. Environmental analysis of paleoceanographic systems based on molybdenum-uranium covariation. Chemical Geology, 268(3): 211-225.

Algeo, T.J. and Twitchett, R.J., 2010. Anomalous Early Triassic sediment fluxes due to elevated weathering rates and their biological consequences. Geology, 38(11): 1023-1026.

Brennecka, G.A., Herrmann, A.D., Algeo, T.J. and Anbar, A.D., 2011. Rapid expansion of oceanic anoxia immediately before the end-Permian mass extinction. Proceedings of the National Academy of Sciences, 108(43): 17631-17634.

Burgess, S.D., Bowring, S. and Shen, S.Z., 2014. High-precision timeline for Earth's most severe extinction. Proceedings of the National Academy of Sciences, 111(9): 3316-3321.

Burton, E.D., Sullivan, L.A., Bush, R.T., Johnston, S.G. and Keene, A.F., 2008. A simple and inexpensive chromium-reducible sulfur method for acid-sulfate soils. Applied Geochemistry, 23: 2759-2766.

Campbell, I.H., Czamanske, G.K., Fedorenko, V.A., Hill, R.I. and Stepanov, V., 1992. Synchronism of the Siberian traps and the Permian-Triassic boundary. Science, 258: 1760-1763.

Canfield, D.E., 2001. Biogeochemistry of sulfur isotopes. Reviews in Mineralogy and Geochemistry, 43(1): 607-636.

Canfield, D.E., Raiswell, R., Westrich, J.T., Reaves, C.M. and Berner, R.A., 1986. The use of chromium reduction in the analysis of reduced inorganic sulfur in sediments and shales. Chemical Geology, 54: 149-155.

Cao, C., Love, G.D., Hays, L.E., Wang, W., Shen, S. and Summons, R.E., 2009. Biogeochemical evidence for euxinic oceans and ecological disturbance presaging the end-Permian mass extinction event. Earth and Planetary Science Letters, 281(3): 188-201.

Carignan, J. and Wen, H., 2007. Scaling NIST SRM 3149 for Se isotope analysis and isotopic variations of natural samples. Chemical Geology, 242: 347-350.

Clark, S.K. and Johnson, T.M., 2010. Selenium stable isotope investigation into selenium biogeochemical cycling in a lacustrine environment: Sweitzer Lake, Colorado. Journal of Environmental Quality, 39: 2200-2210.

Cutter, G.A., 1982. Selenium in reducing waters. Science, 217(4562): 829-831.

Cutter, G.A., 1992. Kinetic controls on metalloid speciation in seawater. Marine Chemistry, 40: 65-80.

Cutter, G.A. and Bruland, K.W., 1984. The marine biogeochemistry of selenium: a re-evaluation. Limnology and Oceanography, 29(6): 1179-1192. 
Cutter, G.A. and Cutter, L.S., 2001. Sources and cycling of selenium in the western and equatorial Atlantic Ocean. Deep-Sea Research II, 48: 2917-2931.

Ellis, A.S., Johnson, T.M., Herbel, M.J. and Bullen, T., 2003. Stable isotope fractionation of selenium by natural microbial consortia. Chemical Geology, 195: 119-129.

Erwin, D.H., Bowring, S.A. and Yugan, J., 2002. End-Permian mass extinction: a review. In: C. Koeberl and K.G. MacLeod (Editors), Catastrophic events and mass extinctions: impacts and beyond. Geological Society of America Special Paper, Boulder, Colorado, pp. 363383.

Fan, H.F., Wen, H., Hu, M. and Zhao, H., 2011. Selenium speciation in Lower Cambrian Seenriched strata in South China and its geological implications. Geochimica et Cosmochimica Acta, 75: 7725-7740.

Farley, K.A., Ward, P.D., Garrison, G.H. and Mukhopadhyay, S., 2005. Absence of extraterrestrial ${ }^{3} \mathrm{He}$ in Permian-Triassic age sedimentary rocks. Earth and Planetary Science Letters, 240: 265-275.

Fenton, S., Grice, K., Twitchett, R.J., Böttcher, M.E., Looy, C.V. and Nabbefeld, B., 2007. Changes in biomarker abundances and sulfur isotopes of pyrite across the PermianTriassic (P/Tr) Schuchert Dal section (East Greenland). Earth and Planetary Science Letters, 262(1): 230-239.

Georgiev, S.V., Stein, H.J., Hannah, J.L., Henderson, C.M. and Algeo, T.J., 2015. Enhanced recycling of organic matter and Os-isotopic evidence for multiple magmatic or meteoritic inputs to the Late Permian Panthalassic Ocean, Opal Creek, Canada. Geochimica et Cosmochimica Acta, 150: 192-210.

Grice, K., Cao, C., Love, G.D., Boettcher, M.E., Twitchett, R.J., Grosjean, E., Summons, R.E., Turgeon, S.C., Dunning, W. and Jin, Y., 2005. Photic Zone Euxinia During the PermianTriassic Superanoxic Event. Science, 307(5710): 706-709.

Gröger, J., Franke, J., Hamer, K. and Schulz, H.D., 2009. Quantitative recovery of elemental sulfur and improved selectivity in a chromium-reducible sulfur-distillation. Geostandards and Geoanalytical Research, 33(1): 17-27.

Henderson, C.M., 1997. Uppermost Permian conodonts and the Permian-Triassic boundary in the Western Canada Sedimentary Basin. Bulletin of Canadian Petroleum Geology, 45: 693-707.

Henderson, C.M., Richards, B.C. and Barclay, J.E., 1994. Permian strata of the Western Canada sedimentary basin. In: G. Mossop and J. Dixon (Editors), The Geological Atlas of western Canada. Canadian Society of Petroleum Geologists and Alberta Research Council, pp. 251-258.

Henderson, P. and Henderson, G.M., 2009. The Cambridge Handbook of Earth Science Data. Cambridge University Press, New York.

Herbel, M.J., Johnson, T.M., Oremland, R.S. and Bullen, T., 2000. Fractionation of selenium isotopes during bacterial respiratory reduction of selenium oxyanions. Geochimica et Cosmochimica Acta, 64(21): 3701-3709.

Hsieh, Y.P. and Shieh, Y.N., 1997. Analysis of reduced inorganic sulfur by diffusion methods: improved apparatus and evaluation for sulfur isotopic studies. Chemical Geology, 137: 255-261.

Hsieh, Y.P. and Yang, C.H., 1989. Diffusion methods for the determination of reduced inorganic sulfur species in sediments. Limnology and Oceanography, 34(6): 1126-1130. 
Johnson, T.M. and Bullen, T., 2003. Selenium isotope fractionation during reduction by Fe(II)Fe(III) hydroxide-sulfate (green rust). Geochimica et Cosmochimica Acta, 67(3): 413419.

Johnson, T.M. and Bullen, T., 2004. Mass-dependent fractionation of selenium and chromium isotopes in low-temperature environments. Reviews in Mineralogy and Geochemistry, 55: 289-317.

Johnson, T.M., Herbel, M.J., Bullen, T.D. and Zawislanski, P.T., 1999. Selenium isotope ratios as indicators of selenium sources and oxyanion reduction. Geochimica et Cosmochimica Acta, 63(18): 2775-2783.

Kajiwara, Y., Yamakita, S., Ishida, K., Ishiga, H. and Imai, A., 1994. Development of a largely anoxic stratified ocean and its temporary massive mixing at the Permian/Triassic boundary supported by the sulfur isotopic record. Palaeogeography, Palaeoclimatology, Palaeoecology, 111(3-4): 367-379.

Korte, C. and Kozur, H.W., 2010. Carbon-isotope stratigraphy across the Permian-Triassic boundary: A review. Journal of Asian Earth Sciences, 39(4): 215-235.

Korte, C., Kozur, H.W., Joachimski, M.M., Strauss, H., Veizer, J. and Schwark, L., 2004. Carbon, sulfur, oxygen and strontium isotope records, organic geochemistry and biostratigraphy across the Permian/Triassic boundary in Abadeh, Iran. International Journal of Earth Sciences, 93(4): 565-581.

Kulp, T.R. and Pratt, L.M., 2004. Speciation and weathering of selenium in Upper Cretaceous chalk and shale from South Dakota and Wyoming, USA. Geochimica et Cosmochimica Acta, 68(18): 3687-3701.

Kump, L.R., Pavlov, A.A. and Arthur, M.A., 2005. Massive release of hydrogen sulfide to the surface ocean and atmosphere during intervals of oceanic anoxia. Geology, 33(5): 397400.

Layton-Matthews, D., Leybourne, M.I., Peter, J.M. and Scott, S.D., 2006. Determination of selenium isotopic ratios by continuous-hydride-generation dynamic-reaction-cell inductively coupled plasma-mass spectrometry. Journal of Analytical Atomic Spectrometry, 21: 41-49.

Layton-Matthews, D., Leybourne, M.I., Peter, J.M., Scott, S.D., Cousens, B. and Eglington, B., 2013. Multiple sources of selenium in ancient seafloor hydrothermal systems: compositional and $\mathrm{Se}, \mathrm{S}$ and $\mathrm{Pb}$ isotopic evidence from volcanic-hosted and volcanicsediment-hosted massive sulfide deposits of the Finlayson Lake District, Yukon, Canada. Geochimica et Cosmochimica Acta, 117: 313-331.

Luo, G., Kump, L.R., Wang, Y., Tong, J., Arthur, M.A., Yang, H., Huang, J., Yin, H. and Xie, S., 2010. Isotopic evidence for an anomalously low oceanic sulfate concentration following end-Permian mass extinction. Earth and Planetary Science Letters, 300: 101111.

Luo, G., Wang, Y., Grice, K., Kershaw, S., Algeo, T.J., Ruan, X., Yang, H., Jia, C. and Xie, S., 2013. Microbial-algal community changes during the latest Permian ecological crisis: Evidence from lipid biomarkers at Cili, South China. Global and Planetary Change, 105: 36-51.

Martens, D.A. and Suarez, D.L., 1997. Selenium speciation of soil/sediment determined with sequential exractions and hydride generation atomic absorption spectrophotometry. Environmental Science and Technology, 31: 133-139. 
Mitchell, K., Couture, R.M., Johnson, T.M., Mason, P.R. and Van Cappellen, P., 2013. Selenium sorption and isotope fractionation: Iron (III) oxides versus iron (II) sulfides. Chemical Geology, 342: 21-28.

Mitchell, K., Mason, P.R.D., Van Cappellen, P., Johnson, T.M., Gill, B.C., Owens, J.D., Ingall, E.D., Reichart, G.-J. and Lyons, T.W., 2012. Selenium as paleo-oceanographic proxy: A first assessment. Geochimica et Cosmochimica Acta, 89: 302-317.

Newton, R.J., Pevitt, E.L., Wignall, P.B. and Bottrell, S.H., 2004. Large shifts in the isotopic composition of seawater sulphate across the Permo-Triassic boundary in northern Italy. Earth and Planetary Science Letters, 218(3): 331-345.

Oremland, R.S., 1990. Measurement of in situ rates of selenate removal by dissimilatory bacterial reduction in sediments. Environmental Science and Technology, 24: 1157-1164.

Proemse, B.C., Grasby, S.E., Wieser, M.E., Mayer, B. and Beauchamp, B., 2013. Molybdenum isotopic evidence for oxic marine conditions during the latest Permian extinction. Geology, 41(9): 967-970.

Rouxel, O., Fouquet, Y. and Ludden, J.N., 2004. Subsurface processes at the Lucky Strike hydrothermal field, Mid-Atlantic Ridge: evidence from sulfur, selenium, and iron isotopes. Geochimica et Cosmochimica Acta, 68(10): 2295-2311.

Rouxel, O., Ludden, J., Carignan, J., Marin, L. and Fouquet, Y., 2002. Natural variations of Se isotopic composition determined by hydride generation multiple collector inductively coupled plasma mass spectrometry. Geochimica et Cosmochimica Acta, 66(18): 31913199.

Rudnick, R.L. and Gao, S., 2014. Composition of the continental crust. Treatise on Geochemistry, 4: 1-51.

Schilling, K., Johnson, T.M. and Mason, P.R.D., 2014. A sequential extraction technique for mass-balanced stable selenium isotope analysis of soil samples. Chemical Geology, 381: 125-130.

Schilling, K., Johnson, T.M. and Wilcke, W., 2011. Selenium partitioning and stable isotope ratios in urban topsoil. Soil Science Society of America Journal, 75(4): 1354-1364.

Schoepfer, S.D., Henderson, C.M., Garrison, G.H., Foriel, J., Ward, P.D., Selby, D., Hower, J.C., Algeo, T.J. and Shen, Y., 2013. Termination of a continent-margin upwelling system at the Permian-Triassic boundary (Opal Creek, Alberta, Canada). Global and Planetary Change, 105: 21-35.

Schoepfer, S.D., Henderson, C.M., Garrison, G.H. and Ward, P.D., 2012. Cessation of a productive coastal upwelling system in the Panthalassic Ocean at the Permian-Triassic Boundary. Palaeogeography, Palaeoclimatology, Palaeoecology, 313-314: 181-188.

Seal, R.R., 2006. Sulfur isotope geochemistry of sulfide minerals. Reviews in Mineralogy and Geochemistry, 61: 633-677.

Shen, J., Schoepfer, S.D., Feng, Q., Zhou, L., Yu, J., Song, H., Wei, H. and Algeo, T.J., 2014. Marine productivity changes during the end-Permian crisis and Early Triassic recovery. Earth-Science Reviews, in press: doi:10.1016/j.earscirev.2014.11.002.

Shore, A.J.T., 2010. Selenium geochemistry and isotopic composition of sediments from the Cariaco Basin and the Bermuda Rise: a comparison between a restricted basin and the open ocean over the last $500 \mathrm{ka}$. Ph.D. Thesis, University of Leicester, Leicester, $307 \mathrm{pp}$.

Song, H., Tong, J., Algeo, T.J., Horacek, M., Qiu, H., Song, H., Tian, L. and Chen, Z.Q., 2013. Large vertical $\delta^{13} \mathrm{C}_{\text {DIC }}$ gradients in Early Triassic seas of the South China craton: 
Implications for oceanographic changes related to Siberian Traps volcanism. Global and Planetary Change, 105: 7-20.

Stüeken, E.E., 2013. A test of the nitrogen-limitation hypothesis for retarded eukaryote radiation: Nitrogen isotopes across a Mesoproterozoic basinal profile. Geochimica et Cosmochimica Acta, 120: 121-139.

Stüeken, E.E., Buick, R. and Anbar, A.D., 2015a. Selenium isotopes support free $\mathrm{O}_{2}$ in the latest Archean Geology, 43(3): 259-262.

Stüeken, E.E., Buick, R., Bekker, A., Catling, D.C., Foriel, J., Guy, B.M., Kah, L.C., Machel, H.G., Montanez, I.P. and Poulton, S.W., 2015b. The evolution of the global selenium cycle: Secular trends in Se isotopes and abundances. Geochimica et Cosmochimica Acta, 162: 109-125.

Stüeken, E.E., Foriel, J., Nelson, B.K., Buick, R. and Catling, D.C., 2013. Selenium isotope analysis of organic-rich shales: advances in sample preparation and isobaric interference correction. Journal of Analytical Atomic Spectrometry, 28(11): 1734-1749.

Ulrich, G.A., Krumholz, L.R. and Suflita, J.M., 1997. A rapid and simple method for estimating sulfate reduction activity and quantifying inorganic sulfides. Applied and Environmental Microbiology, 63(4): 1627-1630.

Ward, P.D., Montgomery, D.R. and Smith, R., 2000. Altered river morphology in South Africa related to the Permian-Triassic extinction. Science, 289: 1740-1743.

Wen, H. and Carignan, J., 2011. Selenium isotopes trace the source and redox processes in the black shale-hosted Se-rich deposits in China. Geochimica et Cosmochimica Acta, 75(6): 1411-1427.

Wen, H., Carignan, J., Chu, X., Fan, H., Cloquet, C., Huang, J., Zhang, Y. and Chang, H., 2014. Selenium isotopes trace anoxic and ferruginous seawater conditions in the Early Cambrian. Chemical Geology, 390: 164-172.

White, R.V., 2002. Earth's biggest 'whodunnit': unravelling the clues in the case of the endPermian mass extinction. Philosophical Transactions of the Royal Society of London B, 360: 2963-2985.

Wignall, P.B. and Twitchett, R.J., 1996. Oceanic anoxia and the end Permian mass extinction. Science, 272(5265): 1155-1158.

Wignall, P.B. and Twitchett, R.J., 2002. Extent, duration, and nature of the Permian-Triassic superanoxic event. Geological Society of America Special Papers: 395-414.

Winguth, A.M. and Maier-Reimer, E., 2005. Causes of the marine productivity and oxygen changes associated with the Permian-Triassic boundary: a reevaluation with ocean general circulation models. Marine Geology, 217(3): 283-304.

Wright, M.T., Parker, d.R. and Amrhein, C., 2003. Critical evaluation of the ability of sequential extraction procedures to quantify discrete forms of selenium in sediments and soils. Environmental Science and Technology, 37: 4709-4716.

Xie, S., Pancost, R.D., Yin, H., Wang, H. and Evershed, R.P., 2005. Two episodes of microbial change coupled with Permo/Triassic faunal mass extinction. Nature, 434(7032): 494-497.

Yu, M., Sun, D., Tian, W., Wang, G., Shen, W. and Xu, N., 2002. Systematic studies on adsorption of trace elements $\mathrm{Pt}, \mathrm{Pd}, \mathrm{Au}, \mathrm{Se}, \mathrm{Te}, \mathrm{As}, \mathrm{Hg}$, Sb on thiol cotton fiber. Analytica Chimica Acta, 456: 147-155.

Zhu, J.M., Johnson, T.M., Clark, S.K., Zhu, X.K. and Wang, X.L., 2014. Selenium redox cycling during weathering of Se-rich shales: A selenium isotope study. Geochimica et Cosmochimica Acta, 126: 228-249. 
Figure 1

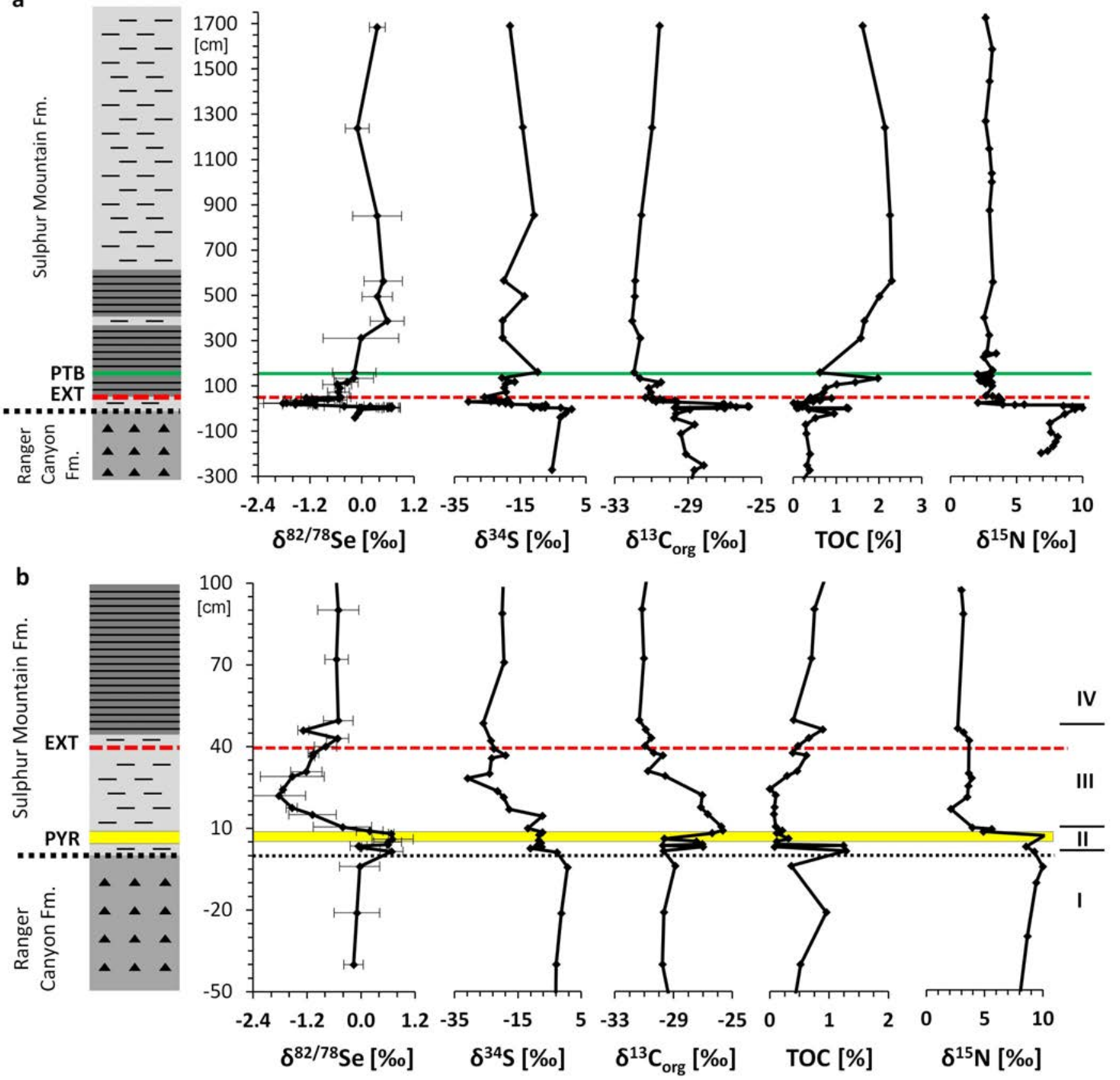


Figure 2

bulk rock powder

$\left(\mathrm{Se}^{-\|}{ }_{\text {org }}, \mathrm{Se}^{\mathrm{IV}}{ }_{\text {ads }}, \mathrm{Se}^{-11}{ }_{\text {pyr }}, \mathrm{Se}^{0}\right)$

REAGENTS: \

$0.1 \mathrm{M} \mathrm{NaOH}$ $90^{\circ} \mathrm{C}, 2$ hours

$$
\downarrow
$$

$2 \mathrm{M} \mathrm{CrCl}_{2}, 6.25 \mathrm{M} \mathrm{HCl}$ room T, 2 days $\quad-----\rightarrow$

$$
\downarrow
$$

$\mathrm{HF}, \mathrm{HNO}_{3}, \mathrm{HClO}_{4}$ $130^{\circ} \mathrm{C}, 2$ days

\section{SPECIES EXTRACTED:}

$\mathrm{Se}_{\text {ads }}^{\mathrm{IV}} \pm$ trace red. Se purified with TCF
$\mathrm{Se}^{-11}{ }_{\mathrm{pyr}} \pm \mathrm{Se}^{0}$

oxidized with $\mathrm{HNO}_{3}+\mathrm{HClO}_{4}$, purified with TCF

$\mathrm{Se}^{-11}$ org $\pm \mathrm{Se}^{0}$ 

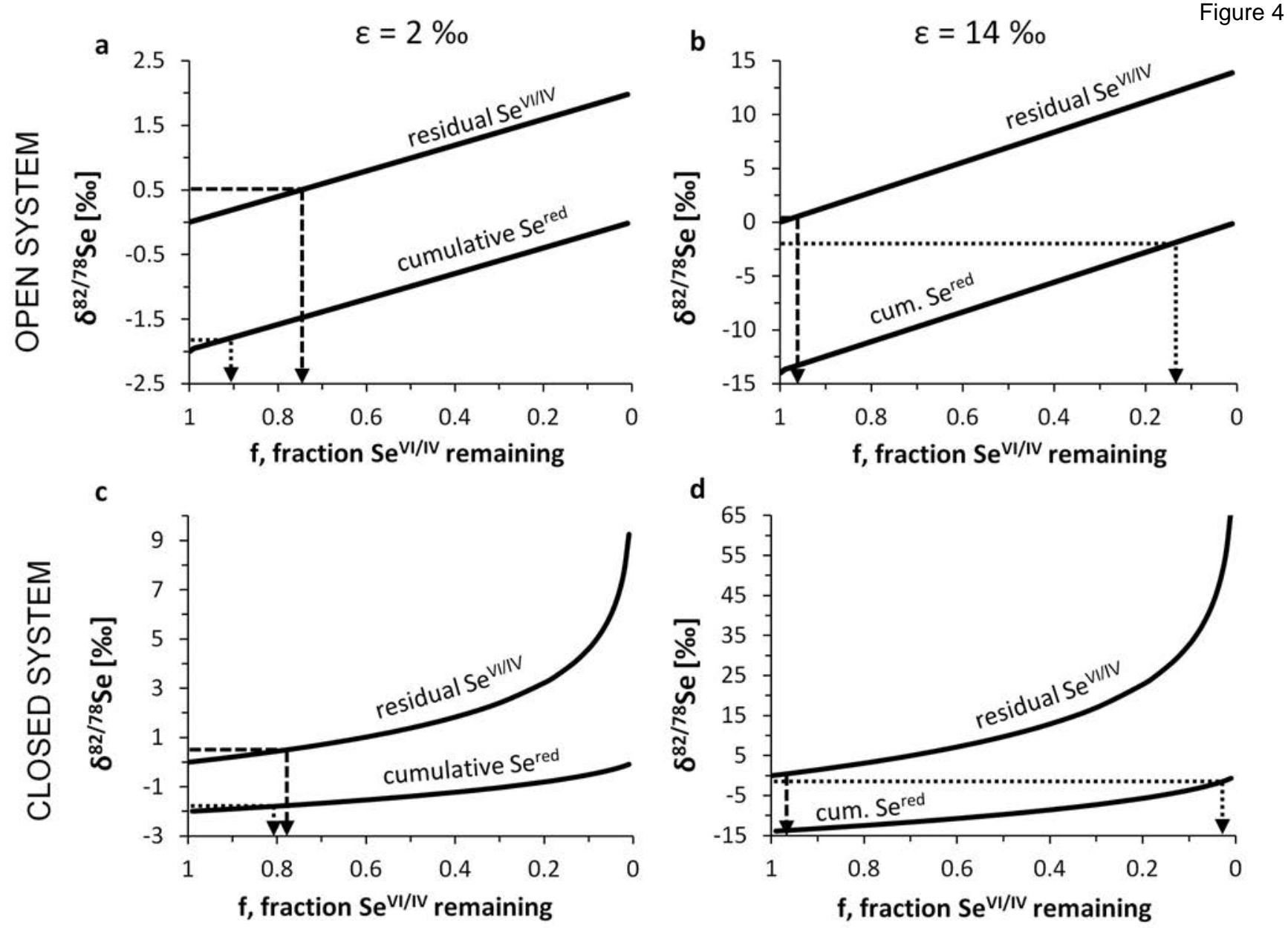


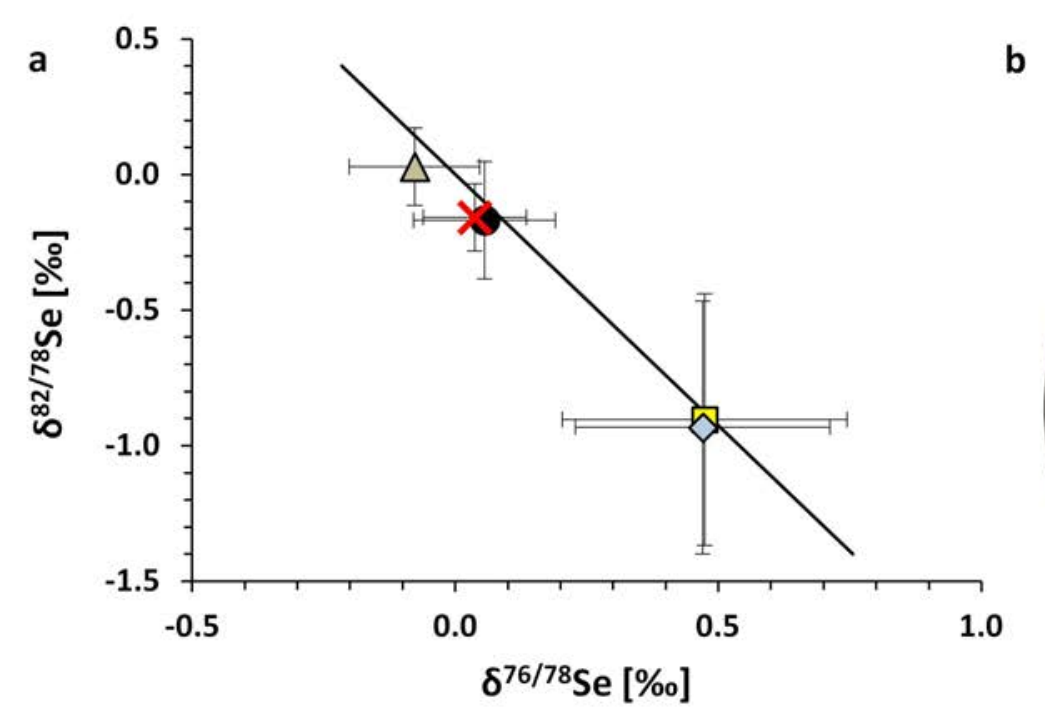

b $8.3+9.4 /-8.3 \% \quad 6.4 \pm 0.4 \%$

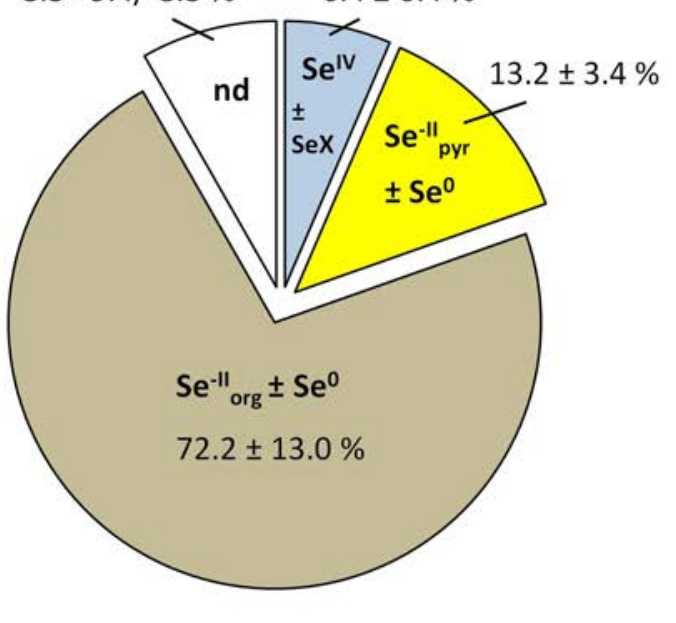


